Nerves innervating copulatory organs show common FMRFamide, FVRlamide, MIP and serotonin immunoreactivity patterns across Dinophilidae (Annelida) indicating their conserved role in copulatory behaviour

Kerbl, Alexandra; Tolstrup, Emilie Winther; Worsaae, Katrine

Published in:

BMC Zoology

DOI:

$10.1186 / \mathrm{s} 40850-019-0045-x$

Publication date:

2019

Document version

Publisher's PDF, also known as Version of record

Document license:

CC BY

Citation for published version (APA):

Kerbl, A., Tolstrup, E. W., \& Worsaae, K. (2019). Nerves innervating copulatory organs show common

FMRFamide, FVRlamide, MIP and serotonin immunoreactivity patterns across Dinophilidae (Annelida) indicating their conserved role in copulatory behaviour. BMC Zoology, 4, [8]. https://doi.org/10.1186/s40850-019-0045-X 


\title{
Nerves innervating copulatory organs show common FMRFamide, FVRlamide, MIP and serotonin immunoreactivity patterns across Dinophilidae (Annelida) indicating their conserved role in copulatory behaviour
}

\author{
Alexandra Kerbl ${ }^{*}$ (ID, Emilie Winther Tolstrup and Katrine Worsaae * (1)
}

\begin{abstract}
Background: Males of the microscopic annelid family Dinophilidae use their prominent glandomuscular copulatory organ (penis) to enzymatically dissolve the female's epidermis and thereafter inject sperm. In order to test for putative conserved copulatory structures and neural orchestration across three dinophilid species, we reconstructed the reproductive myo- and neuroanatomy and mapped immunoreactivity patterns against two specific neurotransmitter markers with reported roles in invertebrate male mating behaviour (FVRlamide, MIP) and three general neural markers (acetylated a-tubulin, serotonin, FMRFamide).

Results: Seminal vesicles (one or two pairs), surrounded by a thin layer of longitudinal and circular muscles and innervated by neurites, are found between testes and copulatory organ in the larger males of Dinophilus vorticoides and Trilobodrilus axi, but are missing in the only $0.05 \mathrm{~mm}$ long D. gyrociliatus dwarf males. The midventral copulatory organ is in all species composed of an outer muscular penis sheath and an inner penis cone. Neurites encircle the organ equatorially, either as a ring-shaped circumpenial fibre mass or as dorsal and ventral commissures, which are connected to the ventrolateral nerve cords. All three examined dinophilids show similar immunoreactivity patterns against serotonin, FMRFamide, and FVRlamide in the neurons surrounding the penis, supporting the hypotheses about the general involvement of these neurotransmitters in copulatory behaviour in dinophilids. Immunoreactivity against MIP is restricted to the circumpenial fibre mass in D. gyrociliatus and commissures around the penis in T. axi (but not found in D. vorticoides), indicating its role in controlling the copulatory organ.
\end{abstract}

Conclusions: The overall myo- and neuroanatomy of the reproductive organs is rather similar in the three studied species, suggesting a common ancestry of the unpaired glandomuscular copulatory organ and its innervation in Dinophilidae. This is furthermore supported by the similar immunoreactivity patterns against the tested neurotransmitters around the penis. Smaller differences in the immunoreactivity patterns around the seminal vesicles and spermioducts might account for additional, individual traits. We thus show morphological support for the putatively conserved role of FMRFamide, FVRlamide, MIP and serotonin in dinophilid copulatory behaviour.

Keywords: Immunohistochemistry, Neurotransmitters, Neuropeptide, CLSM, Neuroregulation, Meiofauna, Neural circuit evolution

\footnotetext{
* Correspondence: alexandra.kerbl@bio.ku.dk; kworsaae@bio.ku.dk

Department of Biology, Marine Biological Section, University of Copenhagen,

Copenhagen, Denmark
}

(c) The Author(s). 2019 Open Access This article is distributed under the terms of the Creative Commons Attribution 4.0 International License (http://creativecommons.org/licenses/by/4.0/), which permits unrestricted use, distribution, and reproduction in any medium, provided you give appropriate credit to the original author(s) and the source, provide a link to the Creative Commons license, and indicate if changes were made. The Creative Commons Public Domain Dedication waiver (http://creativecommons.org/publicdomain/zero/1.0/) applies to the data made available in this article, unless otherwise stated. 


\section{Background}

Invertebrates, including microscopic annelids living among sand grains (interstitially), show various forms of sexual reproduction, including hermaphroditism, and asexual multiplication such as budding or fissure $[1,2]$. Many interstitial groups, and among them the family Dinophilidae Macalister, 1876, show internal fertilization by direct sperm transfer, which diminishes loss of gametes and increases chances of fertilization and thus of successful reproduction [2-5]. Dinophilidae accomplish this by hypodermal injection, where the males enzymatically dissolve the epidermis of the females and transfer their sperm into the female's body by pumping, both accomplished by their glandomuscular copulatory organ [4-7].

Dinophilidae comprises 18 strictly marine species, all characterized by small size, six segments, a dense and broad ventral ciliary band, a muscular pharynx, and complete lack of parapodia, chaetae, or other appendages [2, 8]. The respective species can be distinguished by the number, continuity and arrangement of thin transverse ciliary bands, colour, life strategy as well as the basic architecture of the nervous system $[9,10]$. Despite their simple morphology, male dinophilids exhibit a relatively complex copulatory organ and show mating behaviour, which in case of Trilobodrilus axi Westheide, 1967, even includes a "mating dance" prior to copulation, where males repeatedly move their posterior body to the side when meeting females, or have been shown to crawl alongside each other [7]. Except for Trilobodrilus hermaphroditus Riser, 1999 dinophilids are gonochoristic, with males having a muscular copulatory organ and associated penial glands [8]. Secretions produced by the latter enzymatically create a hole in the epidermis of the female, and sperm is then transferred into the female's body cavity by one or more males [5, 7, 11-13]. When fertilized, the eggs are released by momentary rupture of the epidermis. After release, the eggs become encapsulated in a cocoon-like gelatinous structure, which is either surrounding individual eggs or entire clutches. The animals develop directly, whereby hatching juveniles largely resemble the adults $[2,8,14]$.

Three different life strategies and major morphotypes have been described, exemplified by 1) the monomorphic and hyaline Trilobodrilus axi (being 0.8-1.0 $\mathrm{mm}$ long, and having a life cycle of approximately 1 year including a reproductive period between April and June $[7,14,15]), 2)$ the monomorphic and yellow-orange pigmented Dinophilus vorticoides O. Schmidt, 1848 (having a body length of $1.5-2.5 \mathrm{~mm}$, a long life cycle including an extended, several months long encystment stage [6, $11,16])$, and 3) the sexually dimorphic and hyaline Dinophilus gyrociliatus O. Schmidt, 1857 (forming a diminutive $0.05 \mathrm{~mm}$ long dwarf male in contrast to the $0.7-1.3$ $\mathrm{mm}$ long females, and having a short life cycle of three to four weeks [17-19]).
The male copulatory organ (penis) has been studied to some extend in members of the genus Dinophilus $[4-7,11,20]$. Especially in the dwarf male of D. gyrociliatus, where it takes up approximately one third of their entire body (with the testes filling most of the rest), the details of muscles and glands of the copulatory organ as well as the nerves possibly innervating it have been investigated by ultrastructural and immunohistochemical techniques [4, 19, 20], and especially Traut [8] conducted detailed behavioural observations. While there also have been histological observations of the reproductive organs in Dinophilus cf. taeniatus $[5,6]$ (which now should be regarded as $D$. vorticoides based on its reported location on the Swedish coast (Worsaae et al., unpublished)), Trilobodrilus axi and Trilobodrilus heideri Remane, 1925 [4, 7], we lack a common three-dimensional morphological base in order to compare these organs more reliably. Comprehensive (immunohistochemical) studies have not been conducted on any of these species yet and the homology of the respective structures has not been addressed, although previous studies already hypothesized about functional similarities between at least the two Dinophilus-species [4, 8].

The nervous system and its connections to muscles and glands of the reproductive organs have hitherto only been studied in high detail in D. gyrociliatus [20, 21]. Here, a pair of ganglia (consisting of four neurons each, embracing a central neuropil) is associated with the copulatory organ, and supposedly aids the integration of sensory cues from sensory cells of the posterior end of the animal (surrounding the gonopore) with the information from the anterior part of the body, as well as orchestrates the musculature and glands of the copulatory organ [19-21]. In contrast to these ganglia, the larger males of $D$. vorticoides and $T$. axi instead seem to show a more direct connection to the ventral nervous system $[4,5]$. However, details of the neural innervation of the copulatory organ and the presence and pattern of specific neurotransmitters in this local copulatory circuitry have not been studied previously.

Whereas pan-neural markers can be used to describe the nearly complete layout of the nervous system, neurotransmitters, which are employed by specific neuron populations in the nervous system, can add more detailed information about putative functions of specific regions. Similar to other signalling molecules, they control behaviour by propagating, inhibiting, decreasing, or increasing action potentials of neurons, and thereby lead to excitation or inhibition of the innervated tissue [22]. Neurotransmitters can furthermore be classified into different categories based for example on their structure and formation, e.g., neuropeptides being chains of amino acids, and monoamines being downstream products of aromatic amino acids. Genetically conserved propeptide sequences coding for specific neuropeptides have been found to be correlated to orthologues across larger 
taxonomic groups (families, phyla) or even dating back to the origin of Bilateria [23-25]. Conzelmann et al. [23] demonstrated a conservation of the sequences as well as of the related immunoreactivities in specific cell types across Spiralia, thereby emphasizing the potential of antibodies against these neuropeptides to extrapolate functional subregions of nervous systems across animal groups. Several of these neuropeptides such as FMRFamide (Phe-Met-Arg-Phe), FVRIamide (Phe-Val-Arg-Ile) and MIP (myoinhibitory peptide) have also been shown in functional studies (targeting especially molluscan species as well as ecdysozoans such as the model animal Caenorhabditis elegans (Maupas, 1900) [26-30]) to directly affect the musculature of the reproductive system. Despite this conservation, a previous comparative study of immunoreactivity patterns of 14 antibodies against specific propeptides found vast differences in the nervous systems and especially the brains of $D$. gyrociliatus, $D$. cf. taeniatus (which was collected in the Faroe Islands and therefore also should be referred to as $D$. vorticoides from now on, Worsaae et al., unpublished) and $T$. axi [10]. Focussing on the involvement of the tested neurotransmitters in the demarcated copulatory circuits of three closely related species will allow a better insight into the conservation of function across these closely related species, which will further aid to our understanding of neuroregulation in Spiralia.

In order to provide a detailed description of the neuromuscular anatomy of the male reproductive organs of the three dinophilid species T. axi, D. vorticoides, and $D$. gyrociliatus, we labelled musculature with phalloidin and neurons with antibodies against acetylated $\alpha$-tubulin, the monoamine neurotransmitter serotonin, and three neuropeptides (FMRFamide, FVRIamide and MIP). Whereas we used commercially available antibodies against acetylated $\alpha$-tubulin, serotonin and FMRFamide, the antibodies against FVRIamide and MIP were customized against propeptide sequences of Platynereis dumerilii (Audouin \& Milne-Edwards, 1834) (and show sufficient overlap with sequences of at least one of the tested species, as was shown by Kerbl et al. [10]) and D. gyrociliatus (see Methods for more details). This approach allowed us to compare the reproductive systems in great detail and discuss the evolution and possible functionality of their individual neural components. These hypotheses will be the base for future studies including behavioural assays, and receptor localization.

\section{Results}

\section{Overview of the male reproductive system}

In general, the reproductive systems in all three investigated dinophilid species consist of a medioventral glandomuscular copulatory organ or penis (co, Figs. 1, 2, 3, 4) connected to the testes through spermioducts and one (in Dinophilus vorticoides) or two pairs of seminal vesicles (in
Trilobodrilus axi, sv, Figs. 1a-d, 2a, b, e, f, g). The latter are reduced to simple spermioducts in the dwarf males of Dinophilus gyrociliatus, and although their anterior portions resemble seminal vesicles due to their dense filling with sperm upon maturation, they lack the muscular lining and sphincter muscles observed in the other two species (Figs. 3a, b, 4c).

The paired spermioducts enter the penis bulb from each lateral side, penetrate the muscular penis sheath, and open into the lumen posterior to the penis cone. The lumen, which is also where the majority of the gland ducts seem to lead to, narrows posteroventrally towards the gonopore. The gonopore opens medially between the multiciliated epidermal cells of the ventral ciliary band. More species-specific details are described below.

In all three species the copulatory organ (penis) consists of epithelial cells alternated with gland ducts, with the unicellular glands' cell bodies being located mainly dorsally, laterally and anteriorly to the copulatory organ (not shown). Based on previous ultrastructural and histological studies by Scharnofske [4], there are at least two different unicellular gland types involved, which differ in their vesicular or granular content, but which could not be further analysed in this study. While the copulatory organ is spherical in Trilobodrilus axi (Figs. 1a, b, 2a, b, c, d, 4, 5), it is more elongated in D. gyrociliatus (1.5 times longer than wide, Figs. 1e, f, 3a, b, c, d, e, 4, 5) and in D. vorticoides (2-3 times longer than wide, Figs. 1c, d, 2e, f, g, 4, 5).

\section{Musculature of the male copulatory organ}

The copulatory organ (penis) is located medioventrally above and between the ventral and ventrolateral longitudinal body wall muscle bundles (vlm, vllm, Figs. 2a, b, e, $\mathrm{f}, 3 \mathrm{a}, \mathrm{b}$ ) with thin muscle fibres anchoring it mainly ventral to the body wall in the two larger species $D$. vorticoides and T. axi (am, Figs. 2b, f, 4a, b), while it is directly linked to the mainly longitudinal body wall musculature in D. gyrociliatus dwarf males (Figs. 3a, b, 4c). In all three species the musculature of the copulatory organ consists of an external muscular penis sheath (ps, Figs. 2c, d, g, 3c, d, e, 4a, b, c) and an internal penis cone (pcm, Figs. 2c, d, g, 3d, e, 4a, b, c). The penis sheath is formed mainly by longitudinal muscles extending from the anterior end of the organ towards its ventral opening, where the muscles attach to the sphincter surrounding the gonopore in all three dinophilids (sph2, Figs. 2c, $\mathrm{d}, \mathrm{f}, \mathrm{g}, 3 \mathrm{c}, \mathrm{d}, \mathrm{e})$. In D. gyrociliatus, the muscle fibres are more flattened, thereby giving a more sheath-like and less organized appearance than the muscles constituting the copulatory organ of the other two studied species. Additionally, one or two more anterior sphincter muscles surround the entire penis bulb (sph1, sph3, Figs. 2c, $3 \mathrm{~b}, \mathrm{c}, \mathrm{d}, 4 \mathrm{a}, \mathrm{b}, \mathrm{c})$. In $T$. axi, one of them is situated 


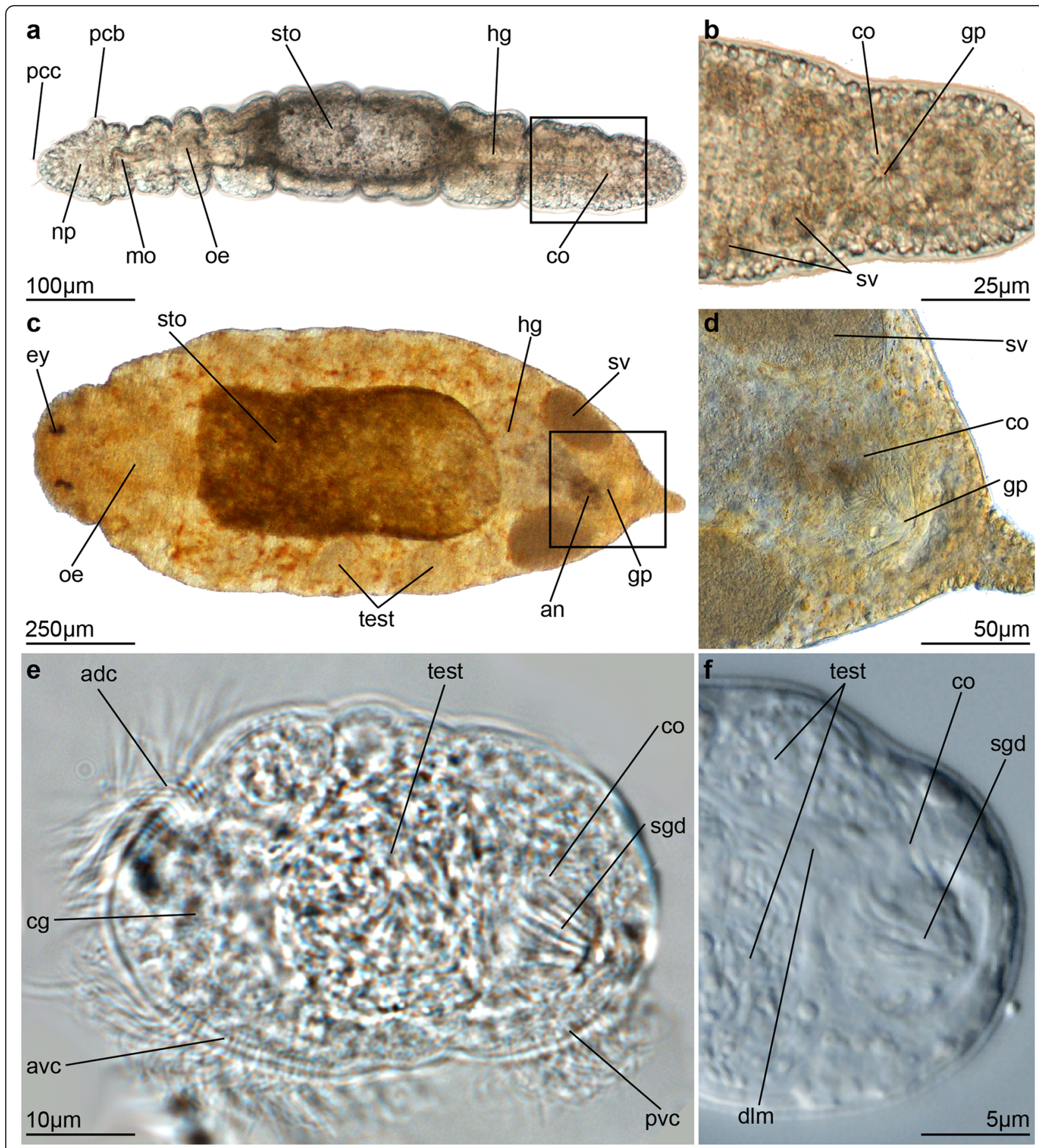

Fig. 1 Light micrographs of adult males of Trilobodrilus axi (a), Dinophilus vorticoides (c) and D. gyrociliatus (e) with details of the copulatory organs ( $\mathbf{b}, \mathbf{d}, \mathbf{f}$. Whole-mounted specimens in $\mathbf{a}, \mathbf{c})$ dorsal view, $\mathbf{b}, \mathbf{d}, \mathbf{f})$ in ventral view, e) in lateral view; anterior oriented to the left. Abbreviations: adc - anterior dorsal ciliation, an - anus, avc - anterior ventral ciliation, cg - cerebral ganglion, co - copulatory organ (penis), dlm dorsal longitudinal muscle, ey - eye, gp - gonopore, hg - hindgut, mo - mouth opening, $n p$ - brain neuropil, oe - oesophagus, pcb - prostomial ciliary band, pcc - prostomial compound cilia, pvc - posterior ventral ciliation, sgd - stylet gland ducts, sto - stomach, sv - seminal vesicle, test - testis

approximately equatorial (where it is connected to the pair of thin longitudinal muscle bundles of the body wall musculature, sph1, Figs. 2c, 4a), and an additional, thinner sphincter is found between it and the one around the gonopore (sph3, Figs. 2c, 4a). An approximately equatorial sphincter is also present in $D$. vorticoides (Figs. 2e, f, g, 4b) and D. gyrociliatus (Figs. 3c, d, 4c), although exact trajectories of muscle fibres are hard to 


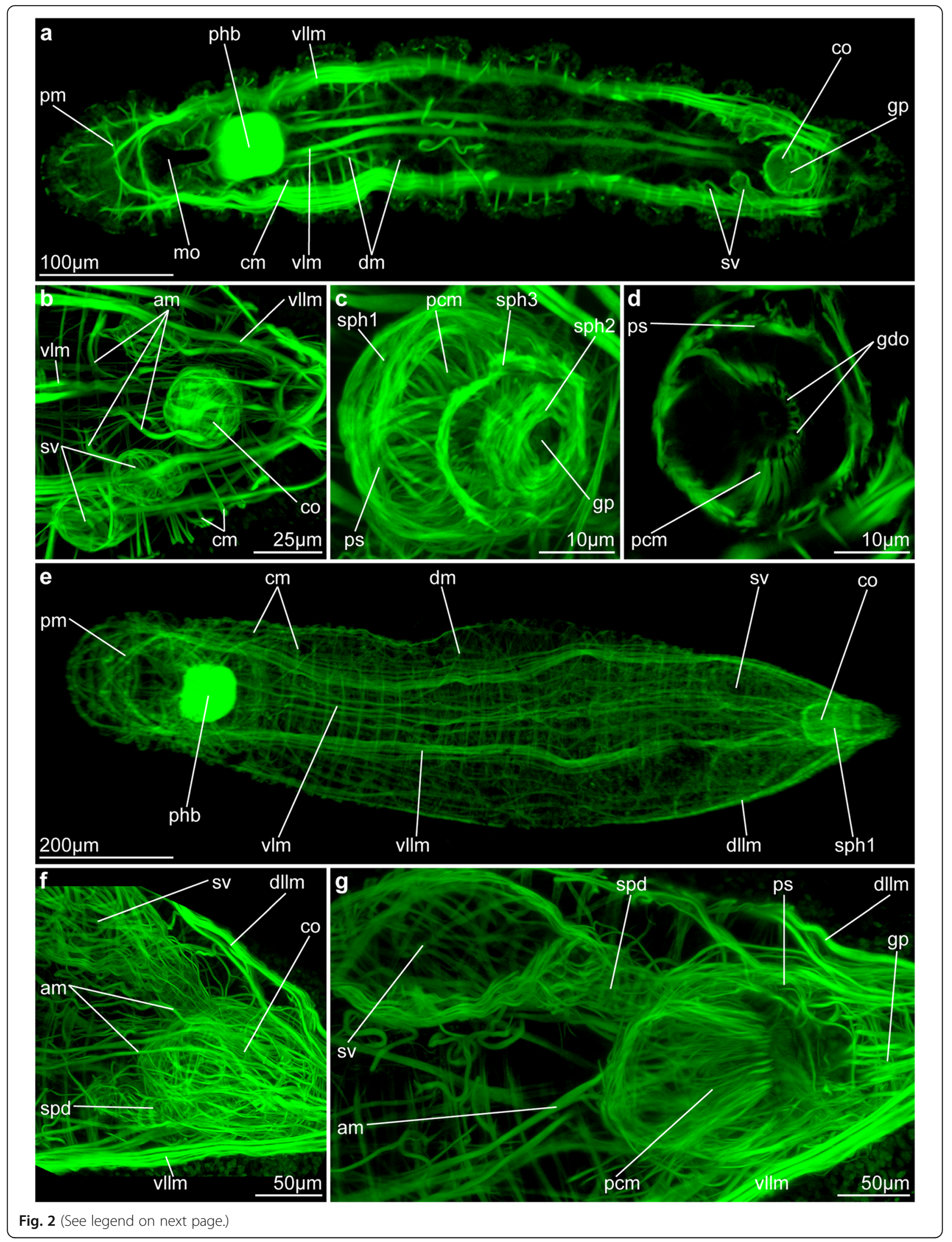


(See figure on previous page.)

Fig. 2 Musculature of adult males of Trilobodrilus axi (a-d) and Dinophilus vorticoides (e-g). Maximum intensity projections of CLSM-image stacks of phalloidin-treated specimens. a) Main ventral musculature in T. axi (ventral view, middle part of z-stack only), b) copulatory organ and seminal vesicles (dorsal view, ventral part of z-stack), c) close up of copulatory organ (ventral view), d) horizontal section through middle part of copulatory organ showing muscles of penis sheath, penis cone and openings of gland ducts. e) Musculature of D. vorticoides (ventral view, ventral half of z-stack), $\mathbf{f}$ ) copulatory organ and right seminal vesicle (lateral view, right half of z-stack), g) sagittal section through copulatory organ and right seminal vesicle (3D crop of z-stack). Abbreviations: am - anchoring muscle, cm - circular muscle, co - copulatory organ (penis), dllm - dorsolateral longitudinal muscle, dm - diagonal muscle, gdo - gland duct openings, gp - gonopore, mo - mouth opening, pcm - penis cone muscle, phb - pharyngeal bulb, pm - prostomial muscle, ps - penis sheath, spd-spermioduct, sph1, 2, 3-sphincter muscles 1, 2, 3, sv - seminal vesicle, vllm - ventrolateral longitudinal muscle, vlm - ventral longitudinal muscle

follow in the latter due to the close proximity of these elements to each other and them being tightly intertwined. Surprisingly, the much more elongated copulatory organ of $D$. vorticoides does not necessitate additional sphincter- or circular muscles to accomplish its functions.

The inner penis cone is in all three species constituted by a thin layer of longitudinal muscle fibres surrounding and supporting the internal gland ducts, whose cell bodies are mostly located outside the penis bulb (data not shown). The exclusively longitudinal muscle fibres of the penis cone originate at the anterior end of the copulatory organ (antero-dorsally in T. axi), follow the penis sheath internally for approximately half the length of the penis cone, and then deviate inwards (Figs. 2d, g, $3 \mathrm{~d}, \mathrm{e}, 4 \mathrm{a}, \mathrm{b}, \mathrm{c})$. In T. axi, the penis cone is located more antero-dorsally and cannot reach the posterior gonopore or even get protruded through it. In $D$. vorticoides and D. gyrociliatus, the penis cone extends more posteriorly (Figs. 2g, 3d, e, 4b, c) with stylet glands forming the

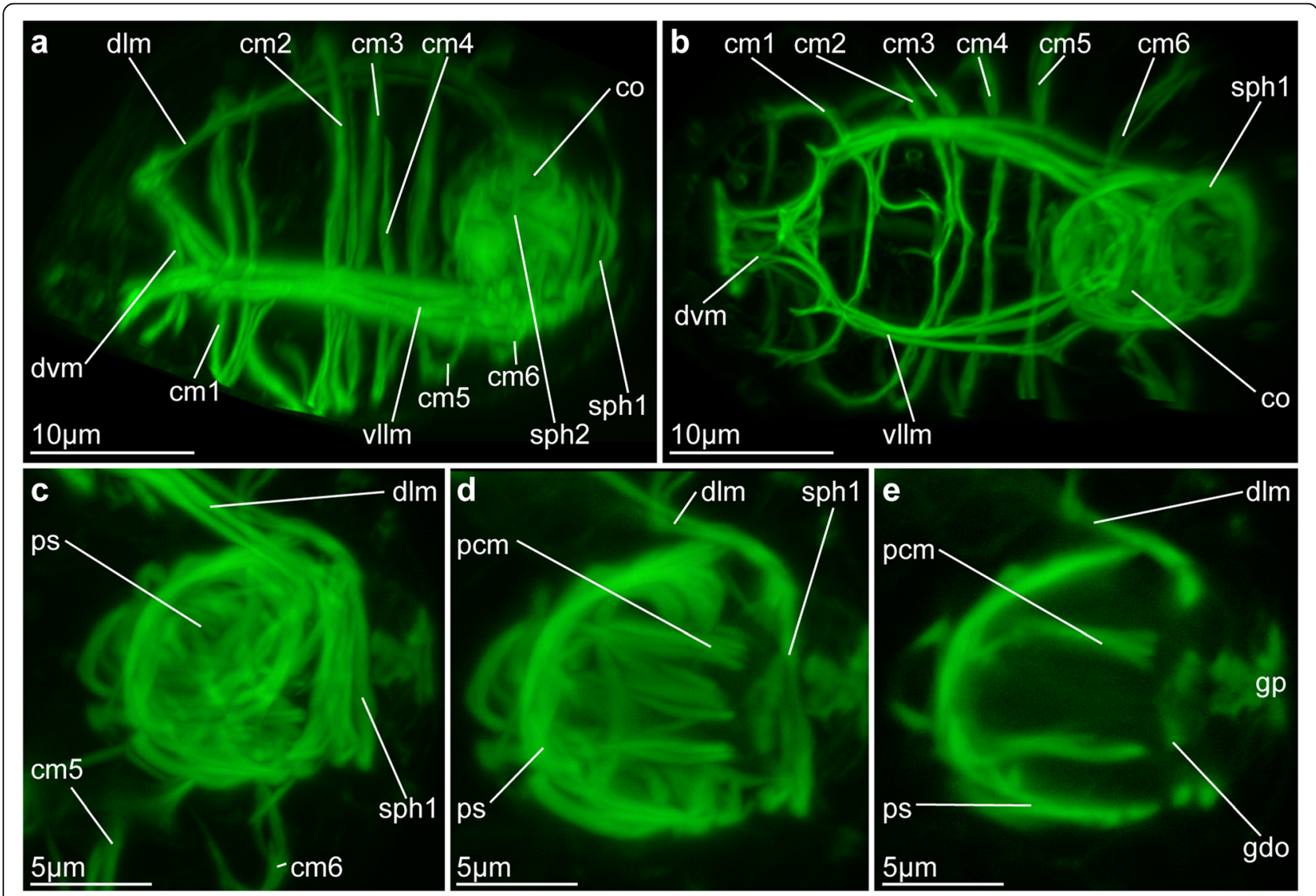

Fig. 3 Musculature of adult dwarf males of Dinophilus gyrociliatus. Maximum intensity projections of CLSM-image stacks of phalloidin-treated specimens. a) Lateral and b) ventral overview (complete z-stack), c-d) details of copulatory organ (lateral views): c) penis sheath (3D crop of zstack), d) sagittal section through lateral part of penis cone and penis sheath, e) sagittal section through middle part of penis sheath, penis cone and openings of gland ducts. Abbreviations: cm1-6 - circular muscle 1-6, co - copulatory organ (penis), dlm - dorsal longitudinal muscle, dvm dorsoventral muscle, gdo - gland duct openings, gp - gonopore, pcm - penis cone muscle, ps - penis sheath, sph1,2 - sphincter muscle 1,2, vllm ventrolateral longitudinal muscle 
tapering end of the penis cone directed towards the gonopore.

The seminal vesicles are situated anteriorly and dorsolaterally to the copulatory organ in T. axi (sv, Figs. 2a, b, 4a) and $D$. vorticoides (Figs. 2e, f, g, 4b), and are surrounded by a thin layer of longitudinal and diagonal muscle fibres with thin muscles anchoring them to the lateral body wall. Thin and innervated (see below) sphincter muscles at the opening passage between the testes and seminal vesicles are only found in T. axi (Figs. 4a, d, 5a, d). The spermioducts of the other two species are lined by few longitudinal and several, quite widely spaced circular muscles (spd, Figs. 2f, g, 4a, b).

No musculature was found around the testes in any species.

\section{Innervation of the male copulatory organ}

In the three here investigated species the architecture of the ventral nervous system is described in detail in previous studies $[9,10,19-21]$ and will thus not be repeated here. In contrast to the high degree of similarities in the musculature and the overall nervous system of the three dinophilid species, the detailed neural innervation of the copulatory organ differs slightly among them: male $T$. axi possess one horizontal, slightly oblique nerve ring around the penis tracing the median sphincter muscle. This circumpenial fibre mass is partly composed of two commissures originating at slightly different points of the ventral cords and embracing the copulatory organ ventrally and dorsally, respectively, with the ventral commissure being more condensed and anterior to the

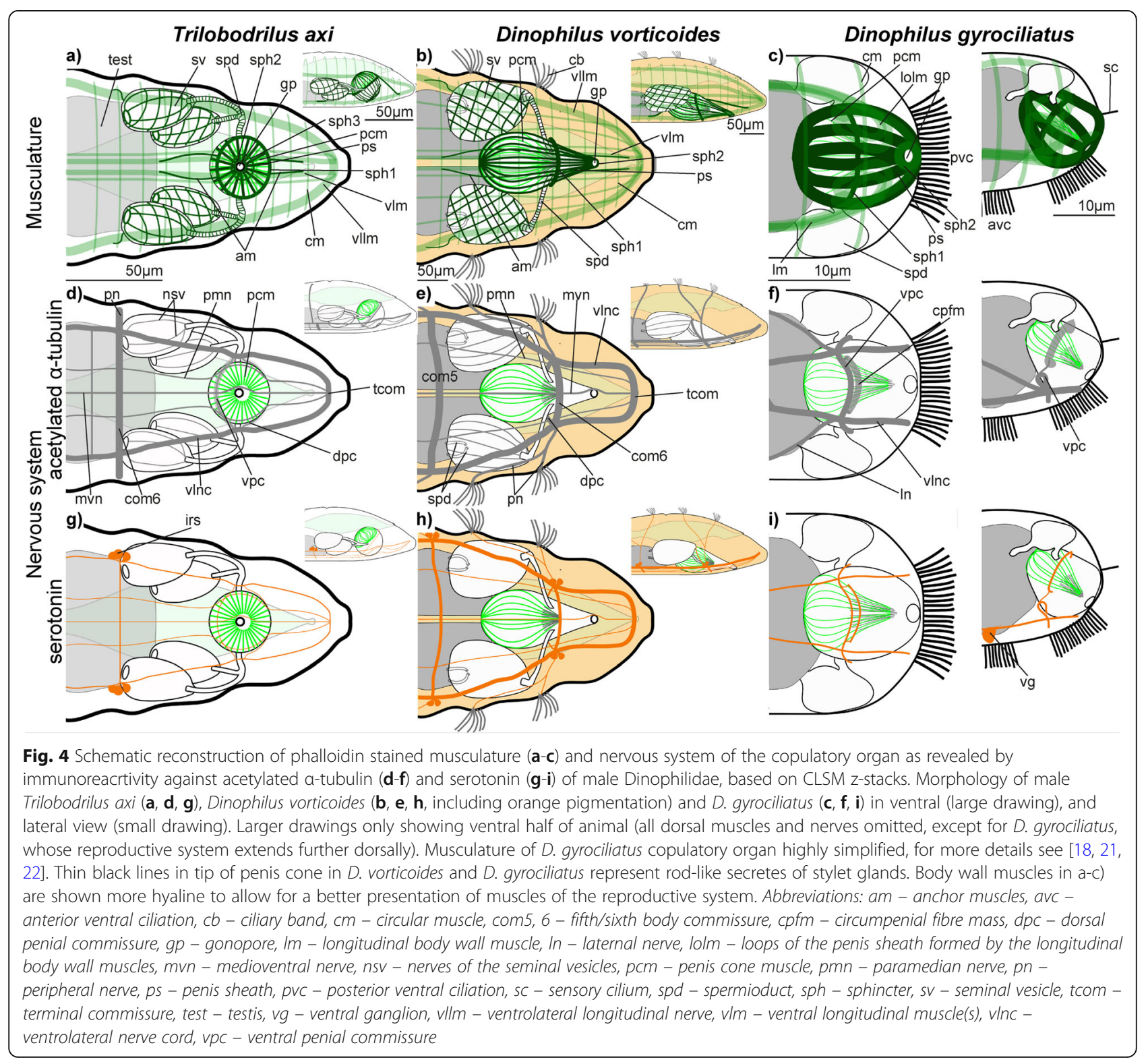




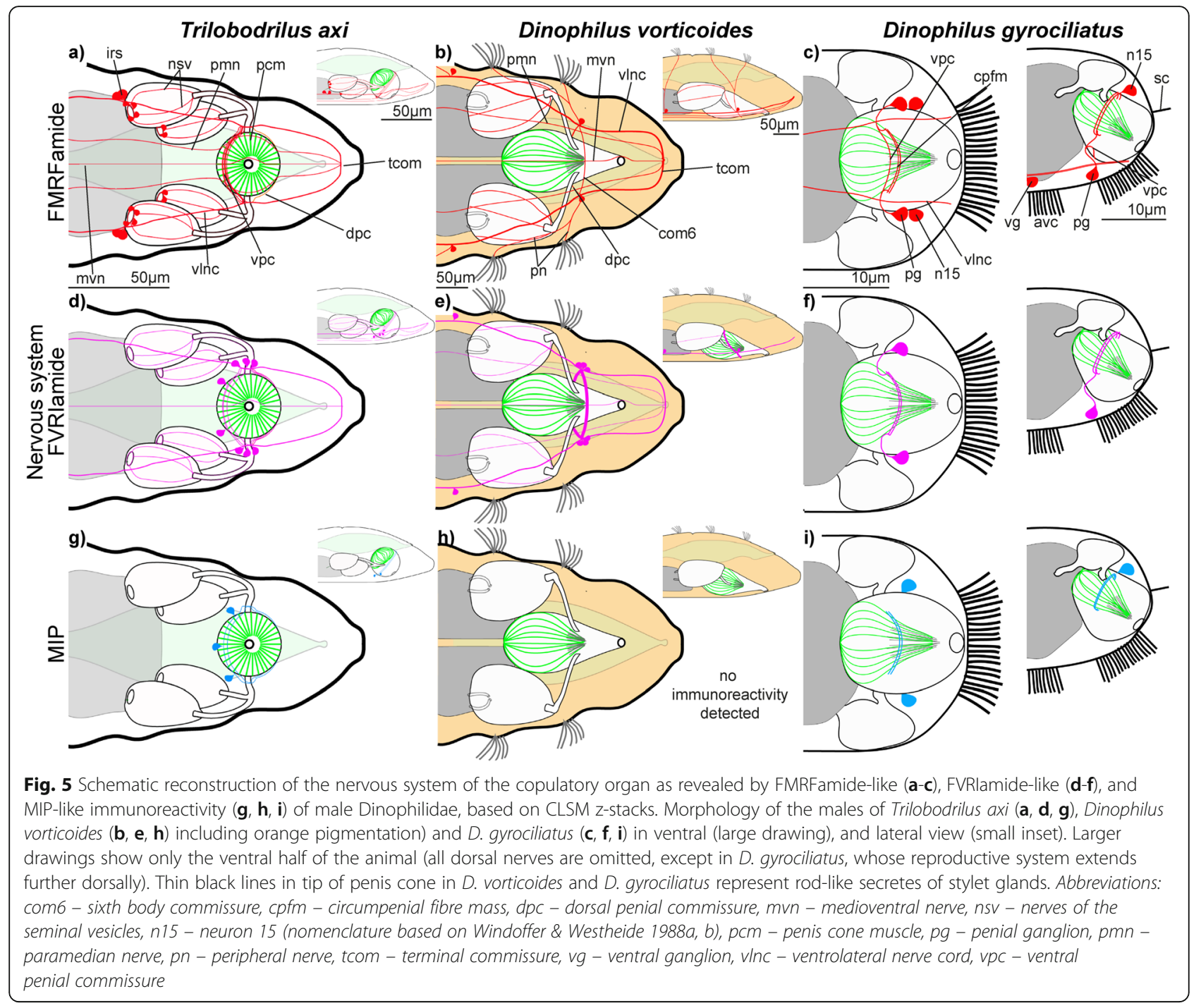

dorsal one (Figs. 4d, 6b, c, d, 7a, d, g, j). Male D. vorticoides also have a ventral and a dorsal commissure; however, here the dorsal commissure is located anterior to the ventral commissure (Figs. 4e, 6f, g, 8b, e, h). Furthermore, the ventral penial commissure is either formed by or fused with the ventral commissure of the sixth body segment (com6), whereas the ventral penial commissure is a separate, independent formation in T. axi posterior to the commissures of the sixth body segment (compare Figs. 4d, 6a, e). Yet another architecture is found in the dwarf male of D. gyrociliatus (Figs. 4, 5, 7b): here, a commissure is formed between the ganglia ventral to the copulatory organ (maybe corresponding to the ventral penial commissure in $D$. vorticoides and T. axi, Figs. 4d, f, 5, 7b), and a ringshaped circumpenial fibre mass is formed around the penis cone within the penis sheath (Figs. $4 \mathrm{~g}, \mathrm{i}, 5 \mathrm{c}, \mathrm{f}$, $h, 7 a, b, 8 c, f, I, k)$, which differs from the other, externally to the muscular penis sheath formed neural structures in $D$. vorticoides and $T$. axi.

Innervation of the seminal vesicles could be traced in the two monomorphic species $D$. vorticoides and $T$. axi, where individual neurites extend from the circumpenial nerve ring along the spermioducts and the seminal vesicles. In $T$. axi, they terminate at the nerve ring surrounding the testes openings (and sphincter muscles), in D. vorticoides we could not find the termination of the longitudinal neurites. These fine neurites are weakly immunoreactive against acetylated $\alpha$-tubulin, but better visible with the specific neurotransmitter immunoreactivities against FMRFamide and FVRIamide (see below). The neural innervation of the spermioducts and seminal vesicles in D. gyrociliatus is much weaker and consists of only one to two neurites, which extend towards the testes (Fig. 4, raw data not shown). 

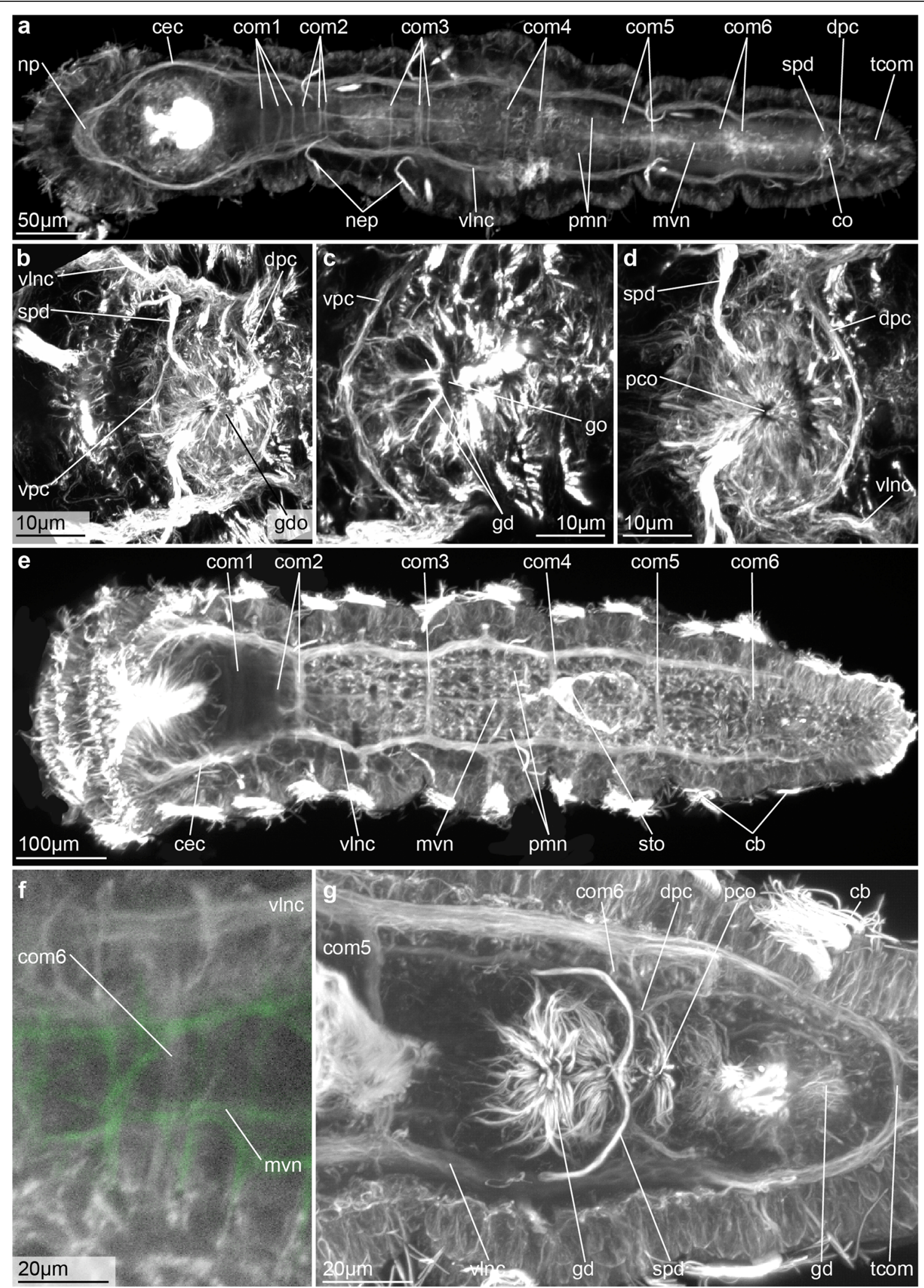

Fig. 6 (See legend on next page.) 
(See figure on previous page.)

Fig. 6 Nervous system of adult males and their copulatory organs in Trilobodrilus axi (a-d) and Dinophilus vorticoides (e-g), as shown from immunoreactivity against acetylated a-tubulin. Maximum intensity projections of CLSM-images. a) Ventral overview of the nervous system of $T$. axi (3D crop of ventral part of $\mathbf{z}$-stack), b-d) nervous system around copulatory organ, showing the ventral penial commissure (b, c), and the dorsal penial commissure (d). e) Ventral overview of the nervous system of D. vorticoides (3D crop of ventral part of $z$-stack), $\mathbf{f}$ ) close up showing the commissure of the sixth body segment (potentially fused with the vpc?) (ventral view, 3D crop of ventral part of z-stack), g) innervation of the copulatory organ (ventral view, ventro-median part of z-stack). Abbreviations: cb - ciliary band, cec - circumoesophageal connective, co copulatory organ (penis), com1-6-commissures of the body segments 1-6, dpc-dorsal penial commissure, gd - gland ducts, gdo - gland duct openings, go - gonopore, mvn - medioventral nerve, nep - nephridium, np - brain neuropil, pco - penis cone opening, pmn - paramedian nerve, spd - spermioduct, sto - stomach, tcom - terminal commissure, vinc - ventrolateral nerve cord

\section{Neurotransmitter immunoreactivity patterns}

Serotonin immunoreactive (serotonin-IR) neurites are found in nearly all parts of the nervous system e.g. in the brain neuropil, ventrolateral nerve cords, paramedian and median nerves as well as some of the commissures and their associated serotonin-IR somata (Figs. 4g, h, i, $6 a,[10,11,14])$. Likewise, the ventral and dorsal penial commissures in T. axi (Figs. 4, 8a, Table 1) and D. vorticoides contain serotonin-IR neurites (Figs. 4, 8b, Table 1 ) as well as the ventral commissure and the circumpenial fibre mass (with stronger immunoreactivity in the dorsal region of the circumpenial fibre mass) in D. gyrociliatus (Figs. 4, 8c, Table 1). There furthermore is one pair of immunoreactive somata in close proximity to the nervous system around the copulatory organs of $D$. vorticoides and D. gyrociliatus, though we could not trace these somata's relation to the immunoreactive neurites of the penial innervation. It was not possible to trace the neurites to the respective somata, so we cannot exclude that the labelled neurites originate from the somata along the ventrolateral nerve cords, and not from somata, which are close to the penial commissures or the circumpenial fibre mass. Serotonin-IR was not detected in the neurites projecting along the seminal vesicles and spermioducts (Figs. 4g, h, i, 8a, b).

FMRFamide-like immunoreactivity is equally abundant to serotonin-IR in the overall nervous system of males of $T$. axi and $D$. vorticoides, but more restricted to the posterior region of the body in the dwarf males of $D$. gyrociliatus. FMRFamide-LIR neurites are thus found in all commissures around and within the copulatory organ (ventral and dorsal penial commissures of T. axi (Figs. 5a, $8 \mathrm{~d}$, Table 1) and D. vorticoides (Figs. 5b, 8e, Table 1), and penial commissure and circumpenial fibre mass in D. gyrociliatus (Figs. 5c, 8e, Table 1)). Several neurites around the seminal vesicles in T. axi (lnsv, Figs. 5a, 8e) and $D$. vorticoides (Figs. 5b, raw data not shown) exhibit FMRFamide-like immunoreactivity, and male $T$. axi
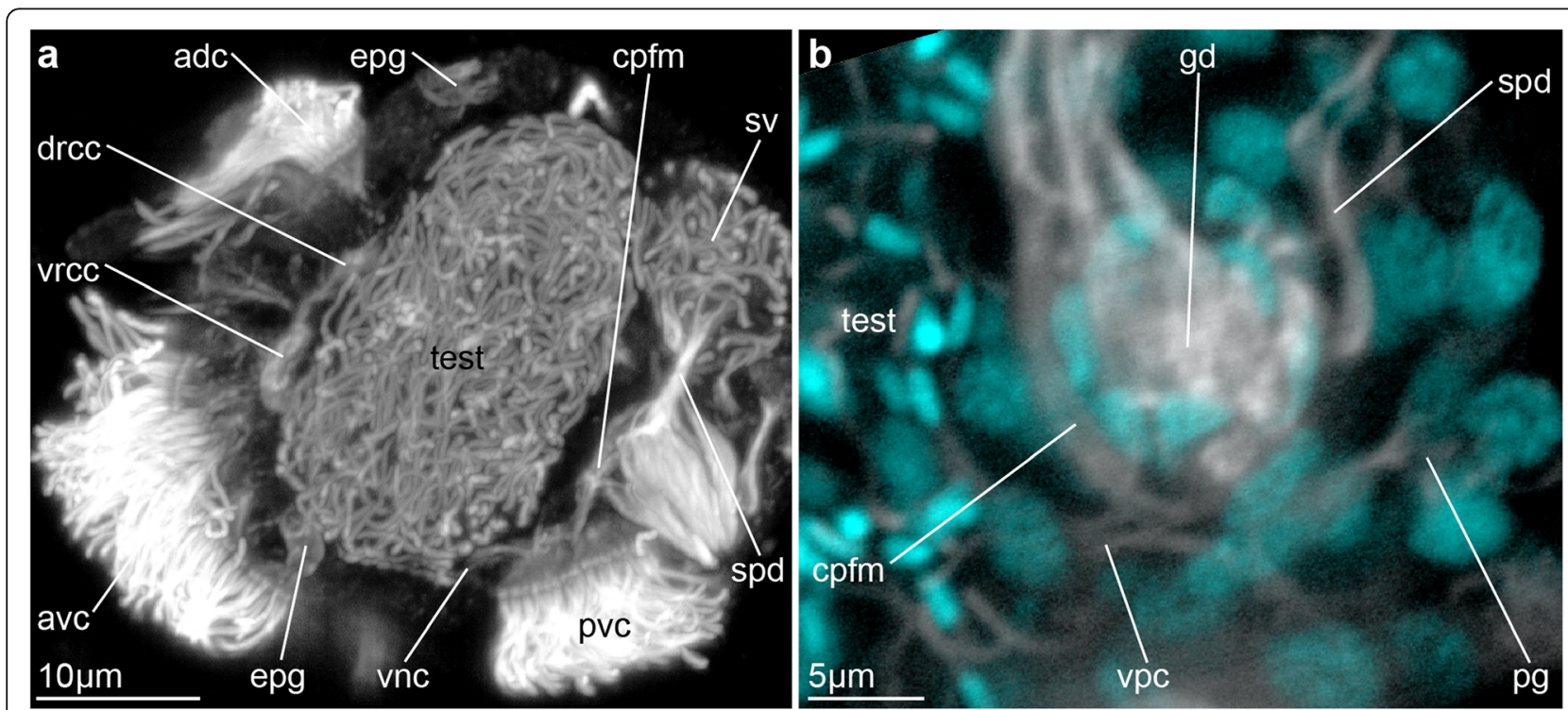

Fig. 7 Nervous system and copulatory organ of adult Dinophilus gyrociliatus dwarf males as shown from immunoreactivity against acetylated atubulin. Maximum intensity projections of CLSM-images. a) Lateral overview of a dwarf male (complete z-stack), and $\mathbf{b}$ ) posterior transverse section through the copulatory organ (also showing nuclei with DAPI-staining in cyan). Abbreviations: adc - anterior dorsal ciliation, avc - anterior ventral ciliation, cpfm - circumpenial fibre mass, drcc - dorsal root of the circumesophageal connective, epg - epidermal gland, gd - gland ducts, pg penis ganglion, pvc - posterior ventral commissure, spd - spermioduct, sv - seminal vesicle, test - testis, vnc - ventral nerve cord, vrcc - ventral root of the circumesophageal commissure 

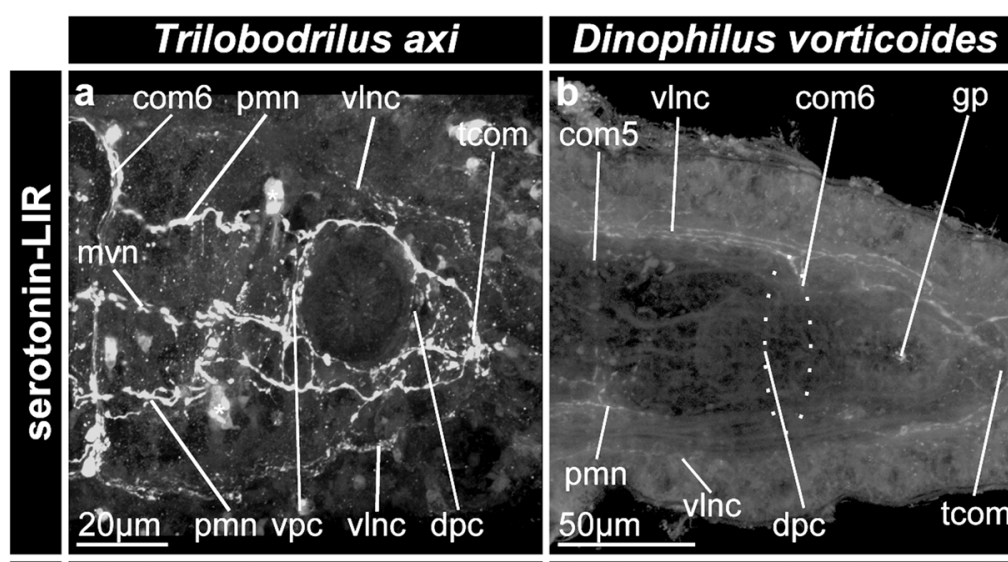

\section{Dinophilus gyrociliatus}
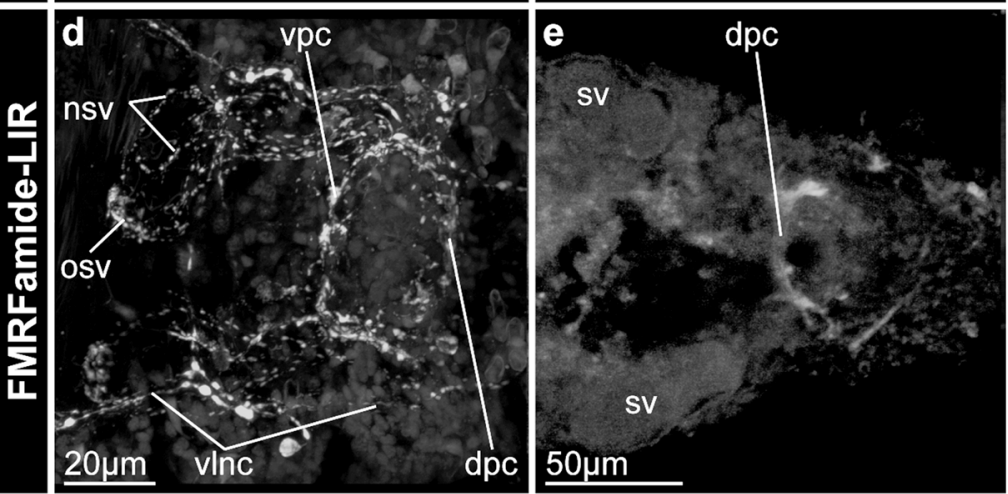

$5 \mu \mathrm{m}$
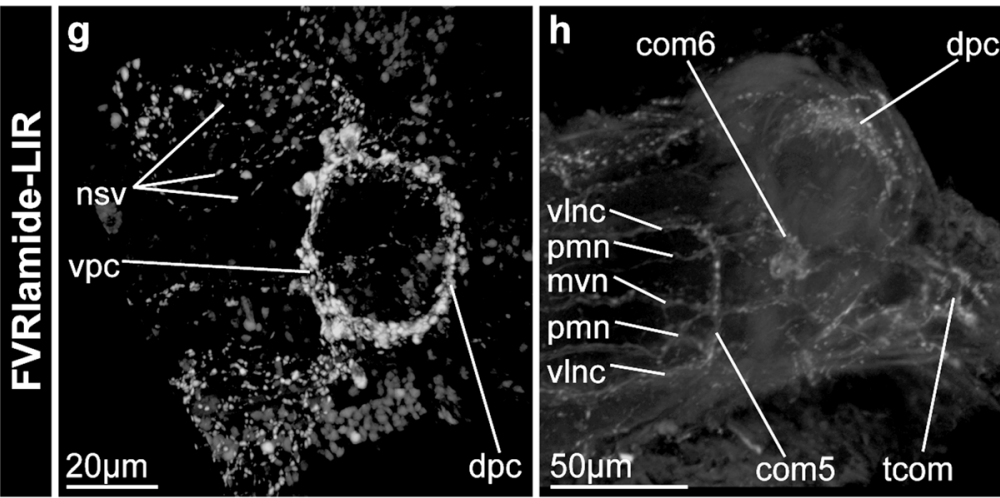

5um C $\mathrm{cpfm}$

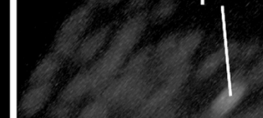

$\mathrm{vpc}$
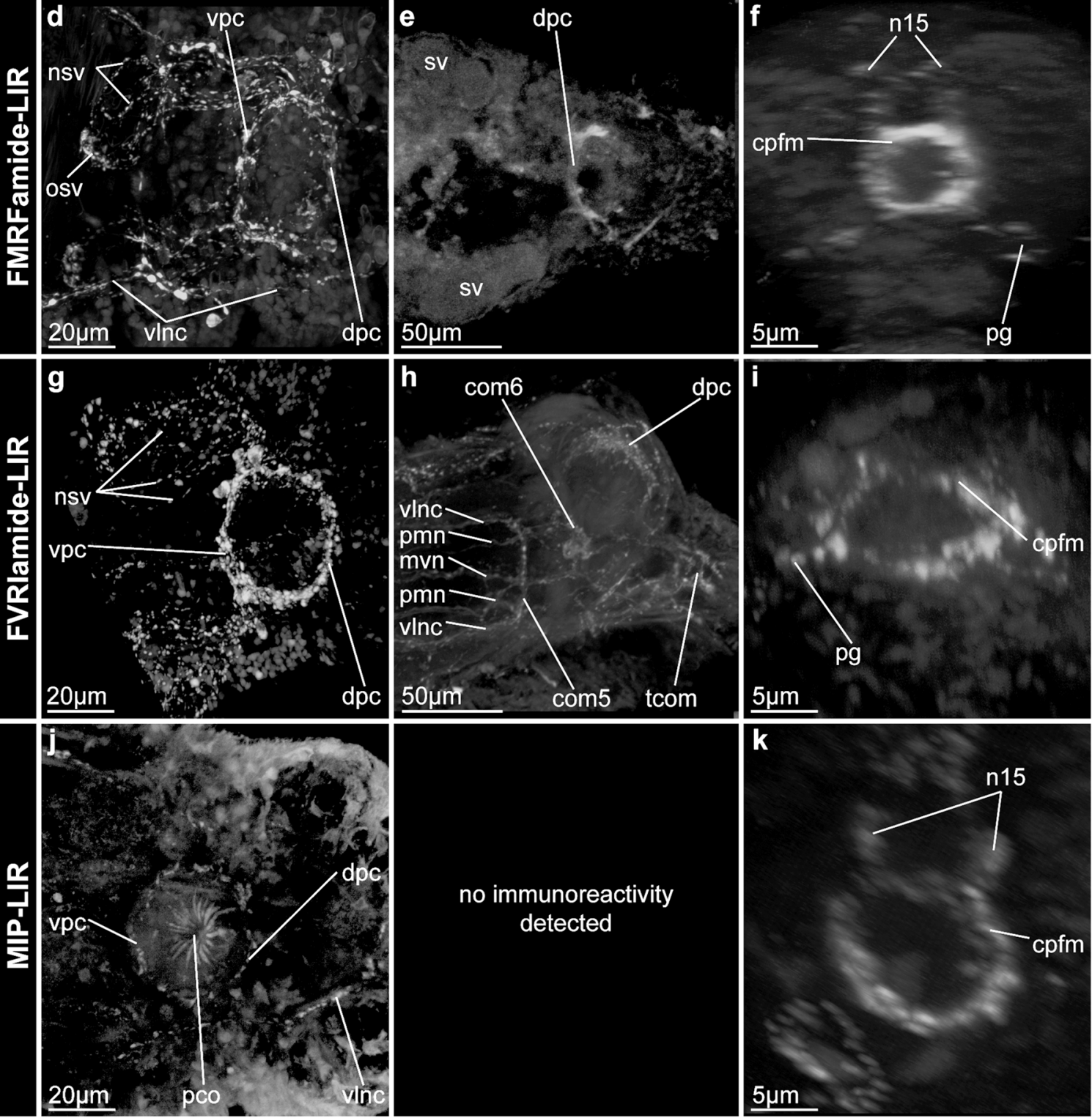

no immunoreactivity detected

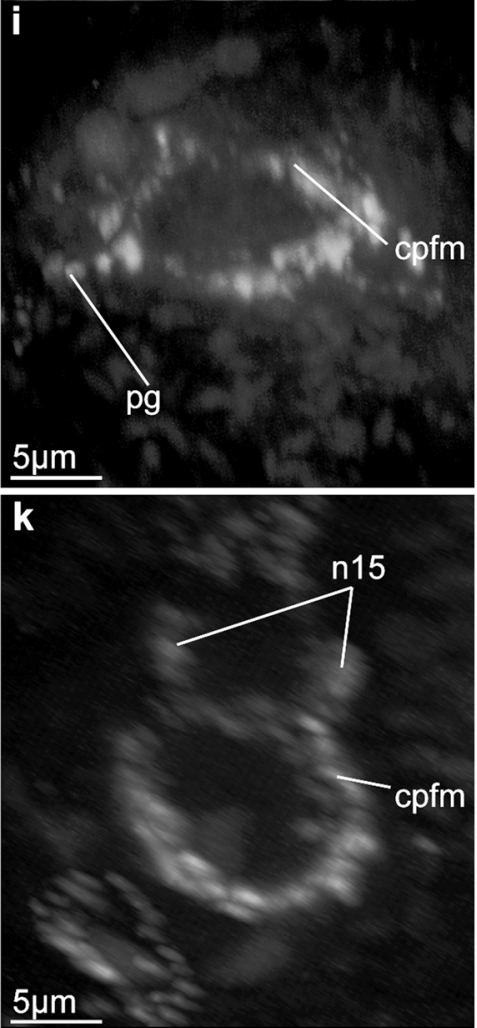

Fig. 8 (See legend on next page.) 
(See figure on previous page.)

Fig. 8 Immunoreactivity against serotonin (a-c), FMRFamide (d-f), FVRlamide ( $\mathbf{g}-\mathbf{i})$, and MIP (j, $\mathbf{k})$ in the nervous system of the copulatory organ in adult males of Trilobodrilus axi ( $\mathbf{a}, \mathbf{d}, \mathbf{g}, \mathbf{j})$, Dinophilus vorticoides $(\mathbf{b}, \mathbf{e}, \mathbf{h})$, and D. gyrociliatus $(\mathbf{c}, \mathbf{f}, \mathbf{i}, \mathbf{k})$. Maximum intensity projections of CLSM-images. a, $b, d, e, g, h, j)$ Ventral view, ventral part of z-stack, c, f, i, k) posterior view, transverse 3D crop through the copulatory organ. For the large D. vorticoides ( $b, e, h)$ only a small subsample of the entire stack has been compiled into a 2D image, omitting some of the traits described in Figs. 4 and 5. Asterisks in (a) mark artefacts (a fold in the animal led to a stronger accumulation of serotonin-IR) and no real immunoreactivity against serotonin of neural elements. Abbreviations: com5, 6 - commissure of the fifth/sixth body segment, cpfm - circumpenial fibre mass, dpc - dorsal penial commissure, gd - gland ducts, gp - gonopore, mvn - medioventral nerve, nsv - nerves of the seminal vesicles, n15 - neurite extending from dorsoposterior sensory neuron 15 (nomenclature based on Windoffer \& Westheide 1988a, b), osv - opening of the seminal vesicles to the testes, pco - penis cone opening, pg - penial gamglion, pmn - paramedian nerve, pvc - posterior ventral ciliation, sv - seminal vesicle, test - test, vlnc - ventrolateral nerve cord, vpc - ventral penial commissure

possess additional FMRFamide-LIR somata around the openings to the testes (osv, Figs. 5a, 8d). No FMRFamide-LIR neurites are lining the spermioducts of D. gyrociliatus, but one pair of neurons of the penial ganglion and one pair of neurons dorsal to the circumpenial fibre mass exhibit immunoreactivity (Fig. 5c).

FVRIamide-LIR neurites are detected around the copulatory organ in T. axi and D. vorticoides: eight (in $T$. axi) or four (in D. vorticoides) immunoreactive somata are arranged around the penis, and project immunoreactive neurites longitudinally along spermioducts and seminal vesicles (Figs. 5d, e, 8g, h, Table 1). Additionally, FVRIamide-LIR neurites without associated immunoreactive somata are forming a ring around the opening of the testes to the seminal vesicles in $T$. axi, probably tracing the sphincter muscle and regulating the transfer of sperm to the seminal vesicles (data not shown). In D. gyrociliatus dwarf males FVRIamide is restricted to the copulatory organ and the associated neurons in the posterior region of the body (Figs. 5f, 8i, Table 1). Here, it is located in the circumpenial fibre mass (Figs. 5f, fig. 8i) and one pair of neurons in the penial ganglia.

Myoinhibitory peptide (MIP)-like immunoreactivity is weak in all studied specimens, thereby complicating its exact localization in the nervous system

Table 1 Immunoreactivity patterns in the nervous system innervating the copulatory organ of Trilobodrilus axi (Tax), Dinophilus vorticoides (Dvo) and D. gyrociliatus (Dgy)

\begin{tabular}{|c|c|c|c|c|c|c|c|c|c|c|c|c|}
\hline & \multicolumn{3}{|l|}{ Serotonin } & \multicolumn{3}{|l|}{ FMRFamide } & \multicolumn{3}{|l|}{ FVRlamide } & \multicolumn{3}{|l|}{ MIP } \\
\hline & Tax & Dvo & Dgy & Tax & Dvo & Dgy & Tax & Dvo & Dgy & Tax & Dvo & Dgy \\
\hline \multicolumn{13}{|c|}{ Central nervous system } \\
\hline$b r^{*}$ & $X(6 / 750)$ & $X(6 / 850)$ & $X(4 / 42)$ & $X(39 / 750)$ & $X(26 / 800)$ & - & $X(16 / 750)$ & $X(8 / 800)$ & - & $X(4 / 750)$ & $X(4 / 800)$ & - \\
\hline vlnc (vns) & $x$ & $x$ & $x$ & $x$ & $x$ & $x$ & $x$ & $x$ & - & - & - & - \\
\hline pmn (vns) & $x$ & $x$ & n.a. & $x$ & $x$ & n.a. & - & - & n.a. & - & - & n.a. \\
\hline mvn (vns) & $x$ & $x$ & n.a. & $x$ & $x$ & n.a. & $x$ & $x$ & n.a. & - & - & n.a. \\
\hline com (vns) & $x$ & $x$ & $x$ & - & - & $x$ & X/- (only anterior ones) & $x$ & - & - & - & - \\
\hline \multicolumn{13}{|c|}{ Innervation of the copulatory organ } \\
\hline com6 & $X(4)$ & X (4) & $x$ & $X(4)$ & $X(2)$ & - & - & $x$ & - & - & - & - \\
\hline vpc & $x$ & n.a. & $X$ & $x$ & n.a. & $x$ & $X(2)$ & n.a. & - & $X(3)$ & - & - \\
\hline$d p c$ & $x$ & $x$ & n.a. & $x$ & $x$ & n.a. & $X(6)$ & $x$ & n.a. & $x$ & - & n.a. \\
\hline cpfm & - & - & $x$ & $x$ & $x$ & $x$ & $X$ & $x$ & $x$ & $X$ & - & $x$ \\
\hline $\mathrm{pg}^{*}$ & n.a. & n.a. & - & n.a. & n.a. & $X(2)$ & n.a. & n.a. & $X(4)$ & n.a. & n.a. & $X(2)$ \\
\hline \multicolumn{13}{|c|}{ Innervation of the seminal vesicles } \\
\hline nsv & - & - & - & $x$ & - & - & $x$ & $x$ & - & - & - & - \\
\hline Osv & - & - & - & $X(3-4)$ & - & - & $x$ & - & - & - & - & - \\
\hline
\end{tabular}

Positive immunoreactivity indicated by " $\mathrm{X}$ ", with number of immunoreactive somata indicated in parentheses. Numbers of immunoreactive somata in brain listed next to the total number of somata of the ganglia (see also [11]). "-" indicates absence of immunoreactivity pattern, "n.a." (not applicable) is used if neural structure is not present or cannot be homologized with the respective neurites of the other species. Sensory cells associated with cerebral or penial ganglia in Dinophilus gyrociliatus dwarf males are included in numbers of brain or penial ganglion cells, indicated by "**"

Abbreviations: br brain, com commissure, com 6 commissure 6 (in D. gyrociliatus, this refers to the commissure between the ventral ganglia), cpfm circumpenial fibre mass, $d p c$ dorsal penial commissure, mvn medioventral nerve, nsv longitudinal neurites along the seminal vesicles, osv nerve ring around the opening of the seminal vesicles, $p g$ penial ganglion, $p m n$ paramedian nerve, vlnc ventrolateral nerve cord, vns ventral nervous system, $v p c$ ventral penial commissure 
around the copulatory organ. In $T$. axi three immunoreactive somata are found anteriomedian to the copulatory organ; one of them anterior, and the other two located lateral on each side of the spherical penis (Fig. 5g, Table 1). The neurites belonging to the latter somata form part of the circumpenial fibre mass around the copulatory organ (Figs. 5g, 8j). No data about the distribution of MIP-like immunoreactivity in the nervous system around the reproductive organs was obtained despite several attempts for $D$. vorticoides. In dwarf males of $D$. gyrociliatus, MIP-LIR neurites are found solely in the circumpenial fibre mass (two to three neurites, Figs. 5i, $8 \mathrm{k}$, Table 1), and potentially in the somata of dorsal sensory neurons, however, the latter pattern is extremely weak and it was not possible to relocate these cells in all tested animals (Fig. 5i).

\section{Discussion}

\section{Function of the dinophilid penis muscles}

Our comparative approach reveals the complex, twolayered penis to be a conserved trait of the annelid family Dinophilidae, which does not seem to be strongly affected by changes in size or life cycle of the species. Combining this study's results with previous histochemical analyses [4,5] and life observations [8] of Dinophilus sp. (mainly $D$. gyrociliatus and $D$. vorticoides), we suggest that the compartmentalization of the copulatory organ into penis sheath and penis cone serves also as a spatial separation of glands with different content and probably also different enzymatic activities (which has however not been further pursued in this study by means of additional experiments). Studies focussing on the Swedish form of $D$. vorticoides have suggested that the glands in the penis cone mainly serve the enzymatic disruption of the female's epidermis, which is accomplished by the cone's protrusion after the adhesive glands of the penis sheath have attached the male gonopore to the female epidermis [5]. This has also been established with behavioural and ultrastructural studies $[4,8]$ in the other two dinophilid species $D$. gyrociliatus and T. axi. The major part of the penis cone protrusion is facilitated by contractions of the penis sheath. Additionally, a contraction of the thin muscle fibres of the penis cone probably causes a widening of the penis cone opening (and thereby an increased flow of enzymes into the lumen of the penis sheath and thereby onto the female's epidermis). Once the enzymes created the hole in the female epidermis, the penis cone is retracted, which is most likely accomplished by both retractions of the muscle fibres of the penis cone and contractions of the circular muscles of the penis sheath, leading to an overall longitudinal extension of the sheath. The retraction of the penis cone also allows free flow of sperm from the testes via the spermioducts into the lumen of the penis sheath. Pumping motions of the penis sheath and cone alternately pump sperm into the female [5], and are further aided by body contractions (especially in the microscopic dwarf male of $D$. gyrociliatus) and the musculature of seminal vesicles and spermioducts, ciliation, and possibly also the pressure within the fully filled testes. Due to the proposed and occasionally observed fast healing properties in these animals the hole in the female closes soon again after being released from the male copulatory organ, possibly supported by enzymes produced by the males and secreted into the open wound $[4,5,8]$. Our preliminary behavioural observations as well as previously published studies suggest a largely similar process in Dinophilus vorticoides and D. gyrociliatus, however, we have less information on T. axi, which differs in lacking stylet glands. This lack is possibly compensated by Trilobodrilus having a somewhat extended courtship behaviour, where the male and the female are crawling alongside each other for a while with occasional sensing tail sweeps of the male prior to attachment and copulation [5, 13, 31-33] and the adhesion provided by the stylet glands may be less needed.

\section{Homologous orchestration of copulation in dinophilids?}

The similar muscle layout of the copulatory organ is not entirely reflected by a similar innervation in the three studied species, yet we depict an overall homology of the neural structures and a similar overall control of the penis pumping motion and transfer of sperm.

The immunoreactivity (IR) against acetylated $\alpha$-tubulin shows an overall similar construct of a prominent nerve ring around the copulatory organ (either continuous or constituted by a ventral and a dorsal commissure between the pair of ventrolateral nerve cords) co-localized with immunoreactivity against serotonin (Figs. 4g, h, I, 8a, c), FMRFamide (Figs. 5a, b, c, 8d, e, f), FVRIamide (Figs. 5d, $\mathrm{e}, \mathrm{f}, 8 \mathrm{~g}, \mathrm{~h}, \mathrm{i})$ and in $T$. axi and D. gyrociliatus against MIP (Figs. 5g, h, 8j, k, Table 1). The position of the circumpenial fibre mass is found between the penis cone and penis sheath in D. gyrociliatus dwarf males, but external to the penis sheath in $T$. axi and D. vorticoides, However, this may reflect that in D. gyrociliatus the body wall is involved in the formation of the muscle layer of the penis sheath [19]. The exact location of the circumpenial nerve ring vis-à-vis the segmental body commissures differs among the three species: In male T. axi it is formed anterior to the copulatory organ and between the sixth body commissure and the terminal commissure (Figs. 4d, 6b, c), representing an additional commissure compared to female $T$. axi (unpublished observations, but see [11]). In males of $D$. vorticoides only the sixth commissure is present, but is here forming a similar circumpenial nerve ring, why the 
additional ventral commissure may be fused with the sixth commissure during evolution (Figs. 4e, 6e, f). The dwarf males of $D$. gyrociliatus show both a circumpenial fibre mass and a ventral commissure between the two penial ganglia (Figs. 4f, 7b). The latter one constitutes the third and posteriormost commissure besides the brain and ventral ganglia commissures, and may be equivalent to the sixth commissure in the other species.

The proposed homologous innervation of the copulatory organ in three dinophilid species also leads us to infer that the mapped neurotransmitters play a conserved role in regulating copulation. FMRFamide and FVRIamide, have been detected in the penis nerve innervating the male copulatory organ in gastropods such as Lymnaea stagnalis (Linnaeus, 1758) and Helix aspera (Linnaeus, 1758) [26, 34-36] by analysing immunoreactivity patterns, which resembles the results of this study, where we found immunoreactivity against these neuropeptides in the ventral and dorsal penial commissures and the circumpenial fibre mass. However, the antibody against FMRFamide used in this study is less specific and thereby labelling a broad range of FMRFamides, which can differ vastly in their action of effector cells and tissues. Studies in the nematode C. elegans for example have shown FMRFamide-like peptides to cause both muscle inactivation or -activation, depending on the respective peptide [27, 37, 38]. We therefore cannot hypothesize about the specific functionality of FMRFamides based on their immunoreactivity patterns, but it is likely that the thus labelled neural elements are involved in orchestrating muscular contractions of penis sheath, seminal vesicles and spermioducts. FVRIamide was shown to inhibit the cycle of muscular contraction and -relaxation in the vasa deferentia of Lymnaea stagnalis [26], which coincides with our findings of FVRIamide-like immunoreactivity in the nerves tracing the seminal vesicles, spermioducts, and penis sheath. The largely overlapping immunoreactivity patterns against FVRIamide and FMRFamide could indicate their opposing roles in coordinating the transport of sperm to the penis bulb as well as of "pumping" movements of the copulatory organ.

Myoinhibitory peptide (MIP) is involved in modulating behaviour according to circadian rhythms, sleep, feeding, life stage transitions, and also mating and copulation in Drosophila melanogaster Meigen, 1830 [30, 39-41]. Remarkably, while MIP seems to act mainly myoinhibitory in insects, recent studies in larvae and juveniles of the macroscopic annelid Platynereis dumerilii focussing on its role in feeding and larval settlement have shown it to act myostimulatory [42-44]. The here presented study characterizes MIPlike immunoreactivity in different parts of the nervous system of the copulatory organ in adult animals, but not the spermioducts or seminal vesicles, thereby separating it from the broader pattern of the previously mentioned immunoreactivity against FMRFamide and FVRIamide. This indicates a more complex orchestration of pumping movements of the copulatory organ possibly involving all of the here tested neurotransmitters, with a likely activating role of MIP on the copulatory organ (such as demonstrated for gut musculature in larvae of $P$. dumerilii [45]). An increase of MIP in the organism would therefore lead to an increased frequency of pumping movements of the penis, such as we observed in the three dinophilid species. Future studies will prove whether the posterior sensory neurons nr. 15 in D. gyrociliatus dwarf males, which are in direct connection to the circumpenial fibre mass around the penis cone and immunoreactive against MIP, and eventually their equivalents in the larger dinophilid species, form a similar circuitry than the one described in larvae of $P$. dumerilii. This would furthermore imply that the direct sensory-neurosecretory mechanism of MIP is not only governing life-cycle transitions (e.g. settlement and feeding [45]), but can be re-deployed in other circuitries, such as the circuit underlying copulation.

Immunoreactivity against serotonin was by far in the highest number of neurons in the nervous system of all three dinophilid species, thereby partly overlapping with especially the immunoreactivity patterns against FVRIamide and FMRFamide (Figs. 4, 5, 8). In previously investigated invertebrate nervous systems, serotonin has been mainly located in motorneurons, and its activating function on muscles and multiciliated cells (used for locomotion) has been established [46-50]. Since previous studies indicate that serotonin can also modify the activity of specific neuropeptides [48], we suggest that besides serotonin acting directly on locomotion in dinophilids (pers. obs. of D. gyrociliatus dwarf males before and after external serotonin application, [50]), it may furthermore act to increase the activity of FMRFamide, FVRIamide and MIP on the musculature of the copulatory organ.

Most of the neuropeptides as well as the monoamine neurotransmitter serotonin are not only found in the nervous system associated with the reproductive organs, but also in the central nervous system [10]. The majority of immunoreactive somata are located around the brain, projecting their neurites through the brain neuropil, the circumesophageal commissures, and the ventrolateral nerve cords towards the posterior end of the body [10] It is therefore likely that the brain and the ventrolateral nerve cords are vital elements of the neural circuitry controlling mating behaviour and copulation, but which are complemented by input from local neuron accumulations such as here shown in the posterior penis ganglion and sensory neurons of D. gyrociliatus dwarf males. 


\section{Conserved roles of specific neuropeptides on muscular activity?}

The unique configuration of the unpaired, medioventral glandomuscular copulatory organ supposedly is a novel formation in Dinophilidae. Whereas the exact phylogenetic position of Dinophilidae within Annelida is still debated, the deeper branching annelid lineages Palaeoannelida and Chaetopteriformia [51] all have external fertilization. The suggested closely related Lobatocerebridae (Martín-Duran et al., unpublished) or Orbiniida [52] likewise have external fertilization except for Parergodrilidae (within Orbiniida), which have internal fertilization. However, they seem to lack true copulatory organs $[53,54]$. Remarkably, three more distantly related meiofaunal annelids have independently evolved somewhat similar, mostly medioventral, to some extend protrusible, muscular unpaired internal copulatory organs: Microphthalmus aberrans (Webster \& Benedict, 1887) [55] is furthermore the only species within its genus possessing an unpaired (slightly offcentered to the right) copulatory organ, supporting its independent origin within the group. In the parasitic/ commensal Histriobdella homari Van Beneden, 1858 the male copulatory organ resembles a bulb, whose internal organisation however remains unresolved (Worsaae, unpublished, [4]). Hrabiella periglandulata possesses a copulatory organ, which likewise resembles a bulb and is additionally associated with a stalked prostatic gland [56], but otherwise does not resemble the previsouly described copulatory organs. Other meiofaunal annelids (e.g., Pisioninae [57], and meiofaunal groups within Syllidae $[58,59]$ and Hesionidae (besides the aforementioned M. aberrans $[60,61])$ mainly have paired copulatory organs, which may be external rather than internal structures with often only one (sometimes weak) muscular sheath surrounding part of the duct or gland complex [35-44, 46, 47].

Although the origin and architecture of the copulatory organs and thereby also their neural control within different annelid families varies, the overall functionality of the neurotransmitters on muscles, glands and other tissues may still be conserved. Neuropeptide function on specific organ systems including the reproductive organs have not been studied in detail in other annelids but in a number of other metazoans, e.g., the model ecdysozoan animals Caenorhabditis elegans [27, 38, 62, 63] and Drosophila melanogaster [40, 64-66], as well as several mollusc species [34, 36, 45, 67], amongst them Helix aspersa and Limnaea stagnalis [34, 68, 69]. Different approaches and treatments, however, have complicated a broad, yet detailed comparison between larger taxonomic groups, which is why information about the conservation of these patterns between closely related groups is vital for our understanding of the evolution of neuromodulatory systems.

\section{Conclusion}

Members of the interstitial annelid family Dinophilidae use hypodermal injection for direct sperm transfer, and the glandomuscular copulatory organ developed in this family is used to both produce a hole in the epidermis of the female and to inject sperm into their bodies $[5,7,8]$. This requires detailed orchestration of muscular and glandular cells, which is amongst others accomplished by the nerves and ganglia in close association to the copulatory organ. We found that in the males of all three species studied here show several defined nerve bundles (commissures) embracing the copulatory organ as well as a strong connection of these structures to the ventral nervous system, but the architecture of this innervation varies slightly between Trilobodrilus axi, Dinophilus vorticoides, and D. gyrociliatus,. The immunoreactivity to (almost) all tested neurotransmitters (serotonin, FMRFamide, FVRIamide, and MIP) in one to several of these nerves strongly suggests their involvement in regulating the musculature of the copulatory organ and thereby also of copulatory behaviour. The conserved patterns of immunoreactive elements across the three tested species combined with our understanding of the animal's behaviour (personal observations and [4, 5, 7, 20, 21, 70]) hereby indicate a conserved functionality of these neurotransmitters across Dinophilidae. Elaborating on our structural data with experimental data from behavioural studies in other annelids and molluscs $[26,28,65]$, we suggest that serotonin, FMRFamide and FVRIamide act on muscles of the copulatory organ, the spermioducts, and the seminal vesicles to support the movement of sperm from the seminal vesicles into the penis sheath [37, 38, 48], while especially MIP (together with the previously mentioned and other, so far untested molecules) might be involved in modulating peristaltic or pumping movements [26, 30, 42]. By studying three closely related species and establishing homology this study offered new proposals on the functionality of neurotransmitters in relation to copulation. Yet, future studies involving the localization of the respective receptors, behavioural observations, and exposure to elevated or decreased transmitter-levels are needed to fully unravel the intricate mechanism of neuroregulation of copulation.

\section{Methods \\ Material}

Adult and juvenile specimens of Trilobodrilus axi Westheide, 1967, were collected from the sandy intertidal beach of List, Sylt, Germany, from extractions of clean sand in early May and late June 2017, and kept at the Marine Biological Section, University of Copenhagen, in filtered seawater (31 per mille salinity), at $15^{\circ} \mathrm{C}$ in the dark.

Adult specimens of Dinophilus vorticoides O. Schmidt, 1848 , were collected from algae in the intertidal close to 
Kaldbak, Faroe Islands, and kept alive in 31 per mille filtered seawater at $10^{\circ} \mathrm{C}$ at the Marine Biological Section, University of Copenhagen for up to two months prior to fixation.

Males of D. vorticoides and T. axi were identified by means of light microscopy, anesthetized using an isotonic solution of $\mathrm{MgCl}_{2}$ (approx. 7\%, but adjusted with a refractometer to 31 per mille) 1:1 with filtered seawater and fixed for immunohistochemical labelling after live observations.

To obtain dwarf males of Dinophilus gyrociliatus O. Schmidt, 1857, cocoons with male and female embryos still in their egg envelopes, which were supposed to hatch within the next $24 \mathrm{~h}$ (for details about the staging, see [19]) were separated from the main culture boxes into smaller dishes in filtered seawater with 28 per mille salinity. The cultures were originally started and maintained by Bertil Åkesson (University of Gothenburg, Sweden) based on animals collected in Xiamen, China, and kept for several years at the Marine Biological Section, University of Copenhagen in the dark at $20^{\circ} \mathrm{C}$. Upon hatching, the dwarf males were anesthetized with isotonic $\mathrm{MgCl}_{2}$ 1:1 with seawater and subsequently fixed for immunohistochemical labelling (see below).

\section{Light microscopy}

Males of the three dinophilid species used for light microscopy were anesthetized, mounted on microscope slides and images were taken with a Olympus DP73 camera mounted on an Olympus IX70 inverted compound microscope (Olympus Corporation, Tokyo, Japan, owned by K. Worsaae) in combination with the CellSens Entry software package v1.6 (Olympus).

\section{Immunohistochemistry and confocal laser scanning microscopy (CLSM)}

Males of the three dinophilid species were first anesthetized, followed by fixation with 3.7\% paraformaldehyde in $0.1 \mathrm{M}$ phosphate buffered saline (PBS) 1:1 with isotonic $\mathrm{MgCl}_{2}$-solution for $1 \mathrm{~h}$ at room temperature (RT) on a rocking board. This step was followed by several rinses in 0.1 M PBS, before the specimens were preincubated in $0.1 \%$ PTA $(0.1 \mathrm{M}$ PBS $+0.1 \%$ Triton-X $+0.25 \%$ bovine albumin serum (BSA) $+5 \%$ sucrose $+0.05 \%$ $\mathrm{NaN}_{3}$ ) for $1 \mathrm{~h}$. All described and following steps were conducted at room temperature (RT) on a rocking board.

Following preincubation, the specimens were incubated in $0.1 \%$ PTA with primary antibodies against acetylated $\boldsymbol{\alpha}$-tubulin (monoclonal mouse antiacetylated $\alpha$-tubulin (T6793, Sigma, St. Louis, USA, RRID:AB_477585, final concentration 1:400) and either serotonin (monoclonal rabbit anti-serotonin (5-HT), S5545, Sigma, RRID:AB_477522, final concentration 1:400),
FMRFamide (polyclonal rabbit anti-FMRFamide, 20,091, Immunostar, RRID:AB_572232, final concentration 1:400), FVRIamide (polyclonal rabbit anti-FVRIamide designed after Platynereis dumerilii sequences [23, 42-44], checked for their sequence similarity by Kerbl et al. [10], and specificity checked by whole mount in situ hybridisation in $P$. dumerilii [71], final concentration 1:1000), or MIP (polyclonal rabbit anti-MIP designed after $P$. dumerilii sequences [23, 42-44], checked for their sequence similarity by Kerbl et al. [10], and specificity checked by morpholino gene knockdown in P. dumerilii [43], final concentration $1: 1000$ ) for $48 \mathrm{~h}$, and subsequently rinsed several times in $0.1 \mathrm{M}$ PBS. We furthermore designed antibodies against the specific sequence of amidated Dinophilus gyrociliatus-MIP (CGWGGNKGMSMWamide, GenScript Biotech Corp, New Jersey, USA), and its immunoreactivity pattern is similar to the ones observed with the previously used Platynereis-antibody. This step preceded the incubation of the specimens in the secondary antibodies (goat anti-mouse antibody conjugated with CY5 (115-175-062, Jackson Immuno-Research, West Grove, USA), and goat anti-rabbit antibody conjugated with TRITC (T5268, Sigma), final concentrations $1: 800$ ) for $24 \mathrm{~h}$. Subsequently, specimens were rinsed in $0.1 \mathrm{M}$ PBS several times and incubated in $0.33 \mu \mathrm{M}$ phalloidin in $0.1 \%$ PTA for $1 \mathrm{~h}$. Finally, specimens were rinsed repeatedly in $0.1 \mathrm{M}$ PBS and mounted in Vectashield (Vector Laboratories, Burlingame, USA). Specificity of primary antibody binding was tested by treating specimens only with secondary antibodies, but otherwise using the same protocol. The reproducibility of the results was checked by replicating the incubations.

The mounted specimens were examined with an Olympus IX81 inverted microscope combined with a Fluoview FV-1000 confocal unit (property of K. Worsaae at the Marine Biological Section, University of Copenhagen, Denmark). Recorded z-stacks were imported in the Imaris 7.6 software package (Bitplane Scientific Software, Zürich, Switzerland) for further three-dimensional investigations. Snapshots were used to export individual sections and smaller stacks from Imaris for plate preparation.

\section{Image preparation}

Brightness, saturation and contrast of LM- and CLSMimages were adjusted in Adobe Photoshop CC 2018 (ADOBE Systems Inc., San Jose, USA) prior to assembling figure plates in Adobe Illustrator CC 2018. The latter was also used to create the schematic drawings.

\section{Abbreviations}

adc: anterior dorsal ciliation; am: anchoring muscle; an: anus; avc: anterior ventral ciliation; cb: ciliary band; cec: circumoesophageal connective; cg: cerebral ganglion; cm: circular muscle; cm1-6: circular muscle 1-6; 
co: copulatory organ (penis); com1-6: body commissure 1-6; cpfm: circumpenial fibre mass; dllm: dorsolateral longitudinal muscle; dlm: dorsal longitudinal muscle; dm: diagonal muscle; dpc: dorsal penial commissure; drcc: dorsal root of the circumesophageal connective; dvm: dorsoventral muscle; epg: epidermal gland; ey: eye; gd: gland ducts; gdo: gland duct openings; gp: gonopore; hg: hindgut; Im: longitudinal body wall muscle; In: laternal nerve; lolm: loops of the penis sheath formed by the longitudinal body wall muscles; mo: mouth opening; mvn: medioventral nerve; n15: neuron 15 (nomenclature based on Windoffer \& Westheide 1988a, b); nep: nephridium; np: brain neuropil; nsv: nerves of the seminal vesicles; oe: oesophagus; osv: opening of the seminal vesicles to the testes; pcb: prostomial ciliary band; pcc: prostomial compound cilia; pcm: penis cone muscle; pco: penis cone opening; pg: penial ganglion; phb: pharyngeal bulb; pm: prostomial muscle; pmn: paramedian nerve; pn: peripheral nerve; ps: penis sheath; pvc: posterior ventral ciliation; sc: sensory cilium; sgd: stylet gland ducts; spd: spermioduct; sph: sphincter; sph1, 2, 3: sphincter muscles 1, 2, 3; sto: stomach; sv: seminal vesicle; tcom: terminal commissure; test: testis; vg: ventral ganglion; vllm: ventrolateral longitudinal muscle; vlm: ventral longitudinal muscle; vlnc: ventrolateral nerve cord; vnc: ventral nerve cord; vpc: ventral penial commissure; vrcc: ventral root of the circumesophageal commissure

\section{Acknowledgments}

The authors want to thank Nicolas Bekkouche and Brett Gonzalez for their help with sampling the animals used in this study, and Gáspár Jékely and Markus Conzelmann for their work on designing the antibodies against FVRlamide and MIP (designed against sequences of Platynereis dumerilii), providing us with aliquots to do the immunohistochemical labelling, and helping us with the production of our own antibodies. We furthermore want to thank two anonymous reviewers for their detailed comments on an earlier version of this manuscript.

\section{Authors' contributions}

AK and KW designed the project. EWT conducted immunohistochemical experiments and CLSM-analyses of the immunoreactivity patterns of Trilobodrilus axi and created the schematic drawings for this species. AK conducted the corresponding experiments on the two Dinophilus-species D. vorticoides and D. gyrociliatus. AK, EWT and KW analysed the data and KW and AK wrote the manuscript. All authors read and agreed to the final version of the submitted text.

\section{Funding}

This work was supported by the Villum Foundation (grant Nr. 1025442) and by the Danish Council for Independent Research (grant Nr. 112709), to Katrine Worsaae. Both funding agencies did not influence the design of the study, the collection of animals, the analysis and interpretation of data and the writing of the manuscript.

\section{Availability of data and materials}

All data analysed in this study are used in the tables and the figures of this article. The original 3D confocal image stacks can be made available after personal contact with the corresponding authors.

\section{Ethics approval and consent to participate}

Not applicable

\section{Consent for publication}

Not applicable

\section{Competing interests}

The authors declare that they have no competing interests.

Received: 4 July 2019 Accepted: 28 August 2019

Published online: 25 October 2019

\section{References}

1. Giere O. Meiobenthology. Springer Science \& Business Media: Berlin; 2013

2. Westheide W. In: Crothers JH, editor. Polychaetes: Interstitial Families. 2nd ed. London: The Linnean Soc. London (Field Studies Council Shrewsbury); 2008.
3. Westheide W. Progenesis as a principle in meiofauna evolution. J Nat Hist. 1987:21:843-54.

4. Scharnofske P. Anatomie, Ultrastruktur und Funktion der männlichen Geschlechtsorgane der Dinophilidae und Histriobdellidae (Annelida, Polychaeta). Osnabrück: PhD-Thesis; 1984. p. 1-92.

5. Jägersten $\mathrm{G}$. Über den Bau des Kopulationsapparates und den Kopulationsmechanismus bei Dinophilus. Zoologiska Bidrag fran Uppsala. 1942;22: $1-16$.

6. Jägersten G. Zur Kenntnis der Morphologie, Enzystierung und Taxonomie von Dinophilus. Kungl Svenska Vetenskapsakad Hand. 1944;21:1-50.

7. Ax P. Das Fortpflanzungsverhalten von Trilobodrilus (Archiannelida, Dinophilidae). Mar Biol. 1968;1:330-5.

8. Westheide W. Dinophilidae Verrill, 1892. In: Beutel RG, Kristensen NP, Leschen R, Purschke G, Westheide W, Frank Z, et al., editors. Handbook of Zoology. Berlin, Boston: Walter de Gruyter GmbH \& Co. KG; 2019. p. 201-16.

9. Müller MCM, Westheide W. Comparative analysis of the nervous systems in presumptive progenetic dinophilid and dorvilleid polychaetes (Annelida) by immunohistochemistry and cLSM. Acta Zool (Stockholm). 2002:83:33-48.

10. Kerbl A, Conzelmann M, Jekely G, Worsaae K. High diversity in neuropeptide immunoreactivity patterns among three closely related species of Dinophilidae (Annelida). J Comp Neurol. 2017;525:3596-635.

11. Jägersten G. Life cycle of Dinophilus, with special reference to the encystment and its dependence on temperature. Oikos. 1951;3:143-65.

12. Sella G, Ramella L. Sexual conflict and mating systems in the dorvilleid genus Ophryotrocha and the dinophilid genus Dinophilus. Hydrobiol. 1999;402:203-13.

13. Korschelt E. Die Gattung Dinophilus und der bei ihr auftretende Geschlechtsdimorphismus. Zool Jahrb Abt allg Zool Physiol Tiere. 1887;2:955-67.

14. Schmidt P, Westheide W. Der Einfluß der Temperatur auf Oocytenentwicklung und Eiablage bei dem interstitiellen Archianneliden Trilobodrilus axi. Mar Biol. 1971;10:94-100.

15. Westheide W. Die Gattung Trilobodrilus (Archiannelida, Polychaeta) von der deutschen Nordseeküste. Helgolander Wiss Meeresunters. 1967;16:207-15.

16. Harmer SF. Notes on the anatomy of Dinophilus. Proc Camb Philos Soc. $1889 ; 6: 119-43$

17. Schmidt O. Die rhabdocoelen Strudelwürmer aus der Umgebung von Krakau. Denkschr. königl. Akad. Wiss., math. naturwiss. Cl. 1858;CLXV:20-46.

18. Fofanova EG, Voronezhskaya EE. The structure of archiannelid Dinophilus gyrociliatus ventral nerve cords. Acta Biol Hung. 2012;63:88-90.

19. Kerbl A, Fofanova EG, Mayorova TD, Voronezhskaya EE, Worsaae K. Comparison of neuromuscular development in two dinophilid species (Annelida) suggests progenetic origin of Dinophilus gyrociliatus. Front Zool. 2016;13:49.

20. Windoffer $\mathrm{R}$, Westheide $\mathrm{W}$. The nervous system of the male Dinophilus gyrociliatus (Polychaeta, Dinophilidae): II. Electron microscopical reconstruction of nervous anatomy and effector cells. J Comp Neurol. 1988;272:475-88.

21. Windoffer $R$, Westheide $W$. The nervous system of the male Dinophilus gyrociliatus (Annelida: Polychaeta). I. Number, types and distribution pattern of sensory cells. Acta Zool (Stockholm). 1988;69:55-64.

22. Strand FL. Neuropeptides. Wiley: Hoboken; 2007.

23. Conzelmann M, Jekely G. Antibodies against conserved amidated neuropeptide epitopes enrich the comparative neurobiology toolbox. Evodevo. 2012;3:1-12.

24. Jekely G. Global view of the evolution and diversity of metazoan neuropeptide signaling. Proc Natl Acad Sci U S A. 2013;110:8702-7.

25. Bauknecht $P$, Jekely $G$. Large-scale combinatorial Deorphanization of Platynereis neuropeptide GPCRs. CellReports. 2015;12:684-93.

26. Filali El Z, Minnen JV, Liu WK, Smit AB, Li KW. Peptidomics analysis of neuropeptides involved in copulatory behavior of the mollusk Lymnaea stagnalis. J Proteome Res. 2006;5:1611-7.

27. Liu T, Kim K, Li C, Barr MM. FMRFamide-like neuropeptides and mechanosensory touch receptor neurons regulate male sexual turning behavior in Caenorhabditis elegans. J Neurosci. 2007;27:7174-82.

28. Di Cristo C, Bovi PD, Di Cosmo A. Role of FMRFamide in the reproduction of Octopus vulgaris: molecular analysis and effect on visual input. Peptides. 2003;24:1525-32.

29. Kim YJ, Bartalska K, Audsley N, Yamanaka N, Yapici N, Lee JY, Kim YC, Markovic M, Isaac E, Tanaka Y, Dickson BJ. MIPs are ancestral ligands for the sex peptide receptor. Proc Natl Acad Sci U S A. 2010;107:6520-5.

30. Jang $\mathrm{Y}-\mathrm{H}$, Chae $\mathrm{H}$-S, Kim $\mathrm{Y}$-J. Female-specific myoinhibitory peptide neurons regulate mating receptivity in Drosophila melanogaster. Nat Commun. 2017;8:1-12. 
31. Charnov EL. Local mate competition and sex ratio in the diploid worm Dinophilus. Int J Inv Reprod \& Devel. 1987;12:223-5.

32. Jennings JB, Donworth PJ. Observations on the life cycle and nutrition of Dinophilus taeniatus Harmer 1889 (Annelida: Polychaeta). Ophelia. 1986;25: 119-37.

33. Traut W. Über die Kopulation bei Dinophilus gyrociliatus (Archiannelida). Zool Anz. 1966;177:402-11.

34. Koene JM, Jansen RF, Maat Ter A, Chase R. A conserved location for the central nervous system control of mating behaviour in gastropod molluscs: evidence from a terrestrial snail. J Exp Biol. 2000;203:1071-80.

35. De Lange RPJ, Van Golen FA, Van Minnen J. Diversity in cell specific coexpression of four neuropeptide genes involved in control of male copulation behaviour in Lymnaea stagnalis. Neuroscience. 1997;78:289-99.

36. Smit AB, Van Kesteren RE, Spijker S, Van Minnen J, Van Golen FA, Jiménez CR, Li KW. Peptidergic modulation of male sexual behavior in Lymnaea stagnalis: structural and functional characterization of -FVamide neuropeptides. J Neurochem. 2003;87:1245-54.

37. Peymen K, Watteyne J, Frooninckx L, Schoofs L, Beets I. The FMRFamide-like peptide family in nematodes. Front Endocrinol. 2014;5:1-21.

38. Lee JS, Shih P-Y, Schaedel ON, Quintero-Cadena P, Rogers AK, Sternberg PW. FMRFamide-like peptides expand the behavioral repertoire of a densely connected nervous system. Proc Natl Acad Sci U S A. 2017;114: E10726-35.

39. Oh Y, Yoon S-E, Zhang Q, Chae H-S, Daubnerová I, Shafer OT, Choe J, Kim Y-J. A homeostatic sleep-stabilizing pathway in Drosophila composed of the sex peptide receptor and its ligand, the myoinhibitory peptide. PLoS Biol. 2014;12:e1001974-15.

40. Hussain A, Üçpunar HK, Zhang M, Loschek LF, Grunwald Kadow IC. Neuropeptides modulate female chemosensory processing upon mating in Drosophila. PLoS Biol. 2016;14:e1002455-28.

41. Kolodziejczyk A, Nässel DR. Myoinhibitory peptide (MIP) immunoreactivity in the visual system of the blowfly Calliphora vomitoria in relation to putative clock neurons and serotonergic neurons. Cell Tiss Res. 2011;345:125-35.

42. Conzelmann M, Williams EA, Tunaru S, Randel N, Shahidi R, Asadulina A, Berger J, Offermanns S, Jekely G. Conserved MIP receptor-ligand pair regulates Platynereis larval settlement. Proc Natl Acad Sci U S A. 2013;110: 8224-9.

43. Williams EA, Conzelmann M, Jekely G. Myoinhibitory peptide regulates feeding in the marine annelid Platynereis. Front Zool. 2015;12:15.

44. Williams EA, Verasztó C, Jasek S, Conzelmann M, Shahidi R, Bauknecht $P$, Mirabeau O, Jékely G. Synaptic and peptidergic connectome of a neurosecretory Centre in the annelid brain. eLife. 2017;6:e26349.

45. Stewart MJ, Wang T, Koene JM, Storey KB, Cummins SF. A "love" dart allohormone identified in the mucous glands of hermaphroditic land snails. J Biol Chem. 2016;291:7938-50.

46. Wu W-H, Cooper RL. Serotonin and synaptic transmission at invertebrate neuromuscular junctions. Exp Neurobiol. 2012;21:101-12.

47. Miron $\mathrm{M}$-J, Anctil M. Serotonin-like immunoreactivity in the central and peripheral nervous system of the scale worm Harmothoe imbricata (Polychaeta). J Comp Neurol. 1988;275:429-40.

48. Lloyd PE, Kupfermann I, Weiss KR. Evidence for parallel actions of a molluscan neuropeptide and serotonin in mediating arousal in Aplysia. Proc Natl Acad Sci U S A. 1984;81:2934-7.

49. Goldberg J, Kater SB. Expression and function of the neurotransmitter serotonin during development of the Helisoma nervous system. Dev Biol. 1989;131:483-95.

50. Fofanova EG, Mayorova TD, Voronezhskaya EE. Paradoxical effect of serotonin on ciliary locomotion of the adult archiannelid worms. Invertebr Zool. 2017;14:114-20.

51. Helm C, Beckers P, Bartolomaeus T, Drukewitz SH, Kourtesis I, Weigert A, Purschke G, Worsaae K, Struck TH, Bleidorn C. Convergent evolution of the ladder-like ventral nerve cord in Annelida. Front Zool. 2018:15:36.

52. Struck TH, Golombek A, Weigert A, Franke FA, Westheide W, Purschke G, Bleidorn C, Halanych KM. The evolution of annelids reveals two adaptive routes to the interstitial realm. Curr Bio. 2015;25:1993-9.

53. Purschke $\mathrm{G}$, Jördens J. Male genital organs in the eulittoral meiofaunal polychaete Stygocapitella subterranea (Annelida, Parergodrilidae): ultrastructure, functional and phylogenetic significance. Zoomorphology. 2007;126:283-97.

54. Purschke G. Male genital organs, spermatogenesis and spermatozoa in the enigmatic terrestrial polychaete Parergodrilus heideri (Annelida, Parergodrilidae). Zoomorphology. 2002;121:125-38.
55. Westheide W. Microphthalmus mahensis sp. n (Annelida, Phyllodocida) together with an annotated key of the genus. Helgoland Mar Res. 2013;67(3):413-22.

56. Rota E. Morphiology and adaptations of Parergodrilus Reisinger and Hrabeiella Pizl \& Chalupsky, two enigmatic soil-dwelling annelids. Ital J Zool. 1998;65(1):75-84.

57. Alikunhi KH. On the reproductive organs of Pisione remota (southern), together with a review of the family Pisionidae (Polychaeta). Proc Ind Acad Sci B. 1951;33(1):14-31.

58. Bührmann C, Westheide W, Purschke G. Ultrastructure of the genital organs in the interstitial syllid Petitia amphophthalma (Annelida, Polychaeta). Acta Zool. (Stockholm). 1996:77:201-11.

59. Kuper $\mathrm{M}$, Westheide $\mathrm{W}$. Ultrastructure of the male reproductive organs in the interstitial annelid Sphaerosyllis hermaphrodita ("Polychaeta," Syllidae). Zoomorphology. 1997;117:13-22.

60. Westheide $W$. Ultrastructure of the genital organs in interstitial polychaetes. I. Structure, development, and function of the copulatory stylets in Microphthalmus cf. listensis. Zoomorphology. 1978;91:101-18.

61. Westheide W. Ultrastructure of the genital organs in interstitial polychaetes. III. Penes and ejaculatory ducts in Hesionides arenaria (Hesionidae). Helgolander Meeresunters. 1982;35:479-88.

62. LeBoeuf B, García LR. Caenorhabditis elegans male copulation circuitry incorporates sex-shared defecation components to promote intromission and sperm transfer. G3. 2017;7:647-62.

63. Barr MM, Garcia LR. Male mating behavior (June 19, 2006). WormBook, ed The C. elegans Reaearch Community, WormBook, https://doi.org/10.1895/ wormbook.1.78.1, http://www.wormbook.org.

64. Tayler TD, Pacheco DA, Hergarden AC, Murthy M, Anderson DJ. A neuropeptide circuit that coordinates sperm transfer and copulation duration in Drosophila. Proc Natl Acad Sci U S A. 2012;109:20697-702.

65. Kim WJ, Jan LY, Jan YN. A PDF/NPF neuropeptide signaling circuitry of male Drosophila melanogaster controls rival-induced prolonged mating. Neuron. 2013;80:1190-205.

66. Stockinger $P$, Kvitsiani D, Rotkopf $S$, Tirián L, Dickson BJ. Neural circuitry that governs Drosophila male courtship behavior. Cell. 2005;121:795-807.

67. Poteryaev DA, Zakharov IS, Balaban PM, Belyavsky AV. A novel neuropeptide precursor gene is expressed in the terrestrial snail central nervous system by a group of neurons that control mating behavior. J Neurobiol. 1998:35:183-97.

68. Koene JM. Allohormones and sensory traps: a fundamental difference between hermaphrodites and gonochorists? Invert Reprod \& Dev. 2005:48:101-7.

69. Morishita F, Furukawa Y, Matsushima O, Minakata H. Regulatory actions of neuropeptides and peptide hormones on the reproduction of molluscs. Can J Zool. 2010:88:825-45.

70. Windoffer R. Immunocytochemische und elektronenmikroskopische Untersuchungen am Nervensystem zweier Dinophilus-Arten mit unterschiedlichem Lebenszyklus. Osnabrück: PhD-Thesis; 1992. p. 1-195.

71. Jékely G, Colombelli J, Hausen H, Guy K, Stelzer E, Nédélec F, Arendt D. Mechanism of phototaxis in marine zooplankton. Nature. 2008:456:395-9.

\section{Publisher's Note}

Springer Nature remains neutral with regard to jurisdictional claims in published maps and institutional affiliations.

Ready to submit your research? Choose BMC and benefit from:

- fast, convenient online submission

- thorough peer review by experienced researchers in your field

- rapid publication on acceptance

- support for research data, including large and complex data types

- gold Open Access which fosters wider collaboration and increased citations

- maximum visibility for your research: over $100 \mathrm{M}$ website views per year

At BMC, research is always in progress.

Learn more biomedcentral.com/submissions 